\title{
The Brain's Asymmetric Frequency Tuning: Asymmetric Behavior Originates from Asymmetric Perception
}

\author{
Arianna Felisatti ${ }^{1, *}$, David Aagten-Murphy ${ }^{1,2}$, Jochen Laubrock ${ }^{1,3}$, Samuel Shaki ${ }^{4}$ and \\ Martin H. Fischer ${ }^{1}$ \\ 1 Department of Psychology, University of Potsdam, Karl-Liebknecht-Strasse 24-25 House 14, \\ D-14476 Potsdam OT Golm, Germany; murphy@neuraltrain.de (D.A.-M.); \\ jochen.laubrock@mhb-fontane.de (J.L.); martinf@uni-potsdam.de (M.H.F.) \\ 2 Neuraltrain $\mathrm{GmbH}$, Friedrichstr. 68, 10117 Berlin, Germany \\ 3 Department of Psychology, Brandenburg Medical School Theodor Fontane Fehrbelliner Straße 38, \\ 16816 Neuruppin, Germany \\ 4 Department of Behavioral Sciences and Psychology, Ariel University, Ariel 40700, Israel; \\ samuel_shaki@hotmail.com \\ * Correspondence: ariannafelisatti@uni-potsdam.de; Tel.: +49-331-977-2895
}

Received: 11 September 2020; Accepted: 10 December 2020; Published: 15 December 2020

\begin{abstract}
To construct a coherent multi-modal percept, vertebrate brains extract low-level features (such as spatial and temporal frequencies) from incoming sensory signals. However, because frequency processing is lateralized with the right hemisphere favouring low frequencies while the left favours higher frequencies, this introduces asymmetries between the hemispheres. Here, we describe how this lateralization shapes the development of several cognitive domains, ranging from visuo-spatial and numerical cognition to language, social cognition, and even aesthetic appreciation, and leads to the emergence of asymmetries in behaviour. We discuss the neuropsychological and educational implications of these emergent asymmetries and suggest future research approaches.
\end{abstract}

Keywords: asymmetry; global/local; spatial frequencies; temporal frequencies; embodied cognition

\section{Introduction}

"The universe is asymmetric and I am persuaded that life, as it is known to us, is a direct result of the asymmetry of the universe or of its indirect consequences."

—Louis Pasteur

Decades of research have revealed that our symmetrical anatomical arrangement of body, eyes, and brain obscures many surprising asymmetries in how our bodies sample the external world and later act upon it. In this review, we aim to address how sensory asymmetries interact with and drive functional changes and-in turn-influence and shape our behaviours, preferences, and even our cultural norms. We begin by describing behavioral, neuropsychological, neuroimaging, and comparative evidence for behavioral asymmetries that result from competition between global and local visual processing. Then, we describe models of processing asymmetries that aim to account for these findings. Based upon these reported results, we then introduce a new theoretical model to account for how brain functional lateralization, spatial frequency tuning, and object location in the external world relative to the observer interact to generate asymmetrical actions. This model is subsequently applied to higher-level cognitive asymmetries to illustrate its broader viability and explanatory power. We end our review by listing a few implications and outstanding questions. 


\section{Global vs. Local Perception}

A growing number of studies suggest that perceptual and behavioral asymmetries originate from hemispheric lateralization. The left hemisphere is more efficient in the selection of fine detail, while the right hemisphere is predominant in the selection of coarse elements [1-3]. Due to the cross-over of the optic fibres, each visual hemi-field projects to the contralateral brain hemisphere. Here, we will specifically review studies on visuo-spatial processing to explain how this organization shapes the development of several cognitive domains.

We begin our review by reminding readers of a seminal behavioral study conducted by Navon (1977) [4]. He presented artificially created hierarchical stimuli in the centre of participants' visual field (see Figure 1, central panel). The stimuli were letter-shaped figures made from many smaller letters, and participants had to respond either to the global or the local letter information with assigned button responses. Importantly, global and local letters could be either response-incongruent or response-congruent (without necessarily being identical). Navon (1977) [4] reported an overall processing speed advantage for the global level, and asymmetrical interference, which was stronger from the global to the local level than in the reverse direction. Together, these findings suggested a coarse-to-fine visual processing sequence. An aspect of the stimuli influencing the salience of the global/local level is the low-pass/high-pass filter. The low-pass filtered images (see Figure 1, left panel) retain the unifying big global structure while removing the numerous little details. On the contrary, high-pass filtered images (see Figure 1, right panel) retain the numerous little details while removing the unifying big global structure. Since this seminal work, there have been numerous behavioural, neuropsychological, neuroimaging, and comparative studies of these "global precedence" and "global/local interference" effects. We review this research here selectively to illustrate the current understanding of visual processing asymmetries.

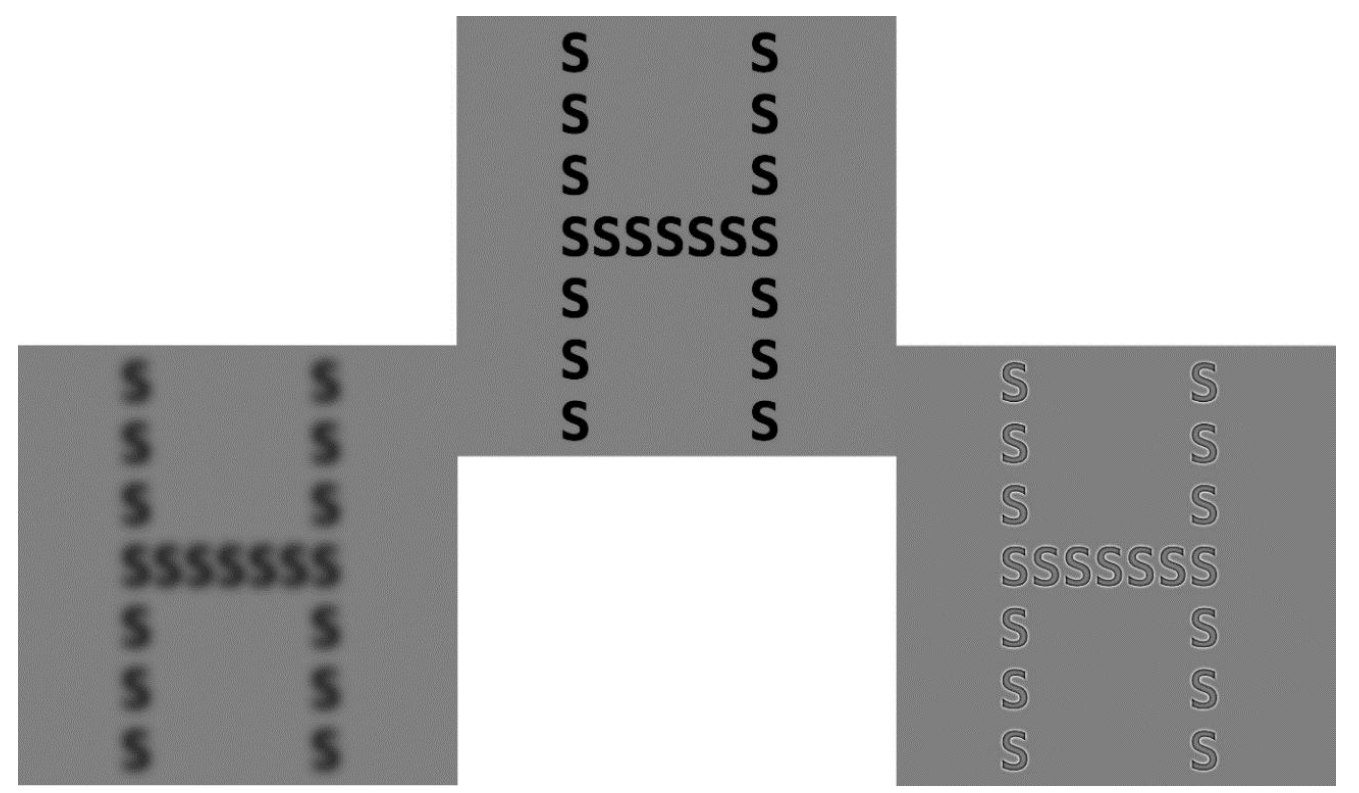

Figure 1. Example of hierarchical stimulus before and after a low-pass/high-pass filter. Central panel: example of hierarchical stimulus with letter " $\mathrm{H}$ " at the global level and letter " $\mathrm{S}$ " at the local level. Left panel: low-pass filtered stimulus. Right panel: high-pass filtered stimulus.

\subsection{Behavioral Evidence}

In addition to the Navon task, there are multiple other sources of behavioural evidence for hemispheric lateralization for global/local processing. Neural development is associated with progressive maturation of the corpus callosum, which is a bundle of fibres supporting inter-hemispheric communication. Investigation of hemispheric asymmetries in healthy populations relies on the use 
of lateralized stimulus presentation by means of hemi-field paradigms (consider Reference [5] for meta-analysis and Reference [6] for methodological considerations). Global stimuli are better perceived when briefly shown on the left side of the fixation point. However, local stimuli are better perceived when briefly displayed on the right side of the fixation point [7-11]. In addition, handedness, which is related to hemispheric asymmetry, influences local/global processing. In everyday life, we use our dominant hand to deal with fine-scale and uni-manual tasks [12]. By testing right-handers, Stanković and Nešić (2018) [13] reported how contraction of the right hand, activating the left hemisphere, correlated with enhanced attention for local stimuli.

Hemispheric specialization for holistic and analytic processing has been considered related to functional lateralization for words and faces. While word recognition recruits the visual word form area, usually confined to the left hemisphere, face recognition recruits the visual face form area, typically found in the right hemisphere (consult Reference [14] for a review). Behavioral experiments using visual half-field tasks showed a right visual field advantage during lexical decision and a left visual field advantage in judging similarities of faces [15]. According to the most influential account, known as input asymmetry principle, the hemispheric predominance for high-level processes is motivated by the types of information required at lower levels [16]. Recently, Brederoo and colleagues (2020) [17] provided evidence to this account reporting correlation between local features and word processing on the left hemisphere, and between global form and face processing on the right hemisphere. Even within the domain of language, holistic processing results in the right visual field advantage as a consequence of left hemisphere involvement [18]. Even if the pattern of right/left predominance for global/holistic processing seems to be stable at the population level, introduction of factors such as handedness and hemispheric dominance for language are linked to completely mirrored or atypical patterns [19-22]. Whatever the direction of the lateralization, its strength is associated with cognitive performances and, as a consequence, with evolutionary advantages [22].

Another example for behavioral asymmetries is pseudo-neglect in bisection tasks. Healthy adults have a tendency to mark the perceived center of visually presented lines to the left of their true center [23]. While this bias is generally interpreted as evidence for an attentional asymmetry, cognitive and motoric factors may also contribute. Depending on the nature of the visual stimulus, higher-level processes may be assessed with the bisection task [24]. For example, when healthy adults mark the midpoints of visually perceived long words, their marks are too close to the beginning of the letter string. This bias is larger than expected from pseudo-neglect and possibly reflects attentional scaling as part of lexical access processes [25-27]. When the stimulus is a long string of digits, its perceived center depends on digit magnitude with a left bias for smaller numbers and a right bias for larger digits, as well as a tendency to bisect plain horizontal lines toward the larger of two different flanker digits [28]. Moreover, the habitual reading direction [29-31] and recent spatial experience [32] are known to influence visuospatial biases in bisection or exploration tasks. For example, the tendency to start reading on the left side of a page in Western cultures seems to induce an anchoring effect for the subsequent bisection judgments with lines and words but not with geometric figures [29]. Relatedly, McManus, Edmondson, and Rodger (1985) [33] evaluated the perceived balance in compositions of abstract shapes. They found that participants marked the balance point of an artistic image slightly to the left of center but that there was considerable inter-individual variability. We will return to aesthetic asymmetries below.

\subsection{Neuropsychological Evidence}

Consider the evidence from neuropsychology in support of hemispheric lateralization for global/local processing. People with occipital, temporal, or parietal brain damage but intact primary visual functions report dissociable performance, depending on the lateralization of their damage (Reference [34] for review). In the bisection task described above, neurologically damaged patients mark the perceived midpoints of horizontally extended plain lines ipsilesional [35-37]. Thus, they seem to ignore the spatial extent of the stimulus into their contralesional visual field. 
Left-side and right-side brain-damaged patients also show difficulties in detecting detail and coarse elements, respectively [38,39]. The corpus callosum plays a crucial role. It supports inter-hemispheric communication but also enhances inter-hemispheric interference between representations $[40,41]$. Interference between global and local processing, which is present in healthy subjects, disappears in patients with a cut corpus callosum [42]. A lesion in the posterior part of the corpus callosum results in selective copying of global elements when using the left hand (controlled by the right hemisphere), and in selective copying of local details when employing the right hand (controlled by the left hemisphere, [43]). The higher number of callosal fibres projecting from the right to the left cortex rather than vice versa seems to be the anatomical expression of asymmetric inhibitory control between the two brain hemispheres [44,45]. We will return to this asymmetry below.

There are other domains of lateralized visual processing, which we briefly mention. First, apperceptive agnosia, the inability to identify unique exemplars of an object under varying illumination or angles of observation or to copy an object, and prosopagnosia, the inability to recognize familiar faces, are usually associated with bilateral or right unilateral occipito-temporal lesions $[46,47]$. Secondly, visual associative agnosia, the ability to see and even copy an object without appreciating its meaning, as well as pure alexia, the inability to read printed words in the absence of object and face recognition deficits, and with, otherwise, intact language processing, appear to be associated with bilateral or left unilateral occipito-temporal lesions [48]. The N170 EEG potential that reflects the early categorization of faces, familiar objects, or words is right-lateralized for faces, bilateral for objects, and left-lateralized for word-like stimuli.

\subsection{Neuroimaging Evidence}

Hemispheric lateralization of global/local processing is further supported by neuroimaging studies. Low-pass filtered images, which retain global structure while removing detail, more strongly engage the right cortical hemisphere, whereas high-pass filtered images, which retain detail while removing global structure, more strongly engage the left cortical hemisphere ([49], see Reference [3] for review). As mentioned in the paragraph on behavioral evidence, even the hemispheric specialization for face and language processing, has been shown to reflect asymmetric processing of low-level properties rather than category-specific knowledge. Left and right occipito-temporal cortical areas are more strongly activated by sine-wave gratings that are frequency-matched to word and face images, respectively [50]. The well-established left hemispheric preference for language, or, more generally, for conspecific communication observed across mammalian species [51,52], and also the right-hemispheric preference for visuo-spatial processing [53], may both build on this early specialization to which we will return in greater detail below.

\subsection{Comparative Evidence}

Lastly, consider the evidence from comparative psychology in support of lateralized global/local processing. Brain lateralization is not a peculiarity of the human brain. All vertebrates have lateralized brains, birds included [51,54]. In daily routines, not only mammals but also birds, amphibians, and fish show biases in two activities that are essential for survival [55]. Feeding is associated with rightward behavior, driven by the left hemisphere [56-58]. Conversely, avoidance of predators and identification of conspecifics are associated with leftward behavior, controlled by the right hemisphere [59-61]. Sovrano (2004) [62] noticed that fish prefer using the left-eye monocular field with familiar stimuli and the right-eye monocular field with unfamiliar stimuli, suggesting right/left hemisphere superiority in discriminating global/local aspects of the visual input, respectively.

The origin of these many perceptual, cognitive, and motoric biases can be found in the fundamental features of a perceptual system driven by global/local processing mechanisms. A left-hemisphere predominance in discrimination between targets that are similar in local features (grains vs. grit), distinguishable through detailed comparison, and a right-hemisphere superiority in discrimination based on larger changes (e.g., predators vs. conspecifics, $[63,64]$ ), which is distinguishable through 
a coarse comparison. Thus, a wide range of non-human species shows functional asymmetries resembling those present in humans with the right and left hemisphere specialized for holistic and analytic processing, respectively. Hemispheric functional asymmetry is supported by an evolutionary explanation since it is present in all vertebrates and entails important advantages: (1) Increase of neural capacity, (2) avoidance of useless duplication of functions, and (3) possibility to execute more tasks simultaneously without interference [64-67].

\section{Global/Local Processing and Spatial Frequencies}

Every visual percept consists of a hierarchical structure with local elements embedded within global ones ([4], see Reference [2], for a review and Reference [68], for recent meta-analysis). For instance, a forest is made up of many trees, a flock is made up of many sheep, and a word is made up of many letters. As a result, local and global image components can be conveyed by different ranges of spatial frequencies (SFs), [1,69-72]. SF is a measure of how often a sine wave pattern of light intensity repeats per unit of distance across the visual field. Much like complex sounds can be constructed from the superposition of simple periodic waves of temporal frequencies (TFs), complex visual stimuli can be thought of as being composed of different spatial frequencies with various orientations and phases. Perceptual systems solve the inverse task known as decomposition. The hierarchical composition of natural stimuli is heavily exploited by convolutional neural networks, which is the currently most successful "artificial intelligence" object detection models $[73,74]$. These are explicitly motivated by hierarchical processing in human object perception and closely correspond to the feed-forward pass in the human ventral stream [75].

It is well known that complex sounds can be decomposed by Fourier transform into their frequency spectra, which is a task approximated by the cochlea and primary auditory cortex (A1). Similarly, complex visual stimuli can be decomposed into their underlying spatial frequency spectra that contains information about the energy or power of the individual frequencies. Simple cells in early visual cortex seems (V1) can be conceptualized as spatial frequency analyzers. In any visual scene, coarse shapes represent few dark-light oscillations across space (Low SF range, LSFs, see Figure 1, left panel), while fine details correspond to many dark-light cycles per unit of space (High SF range, HSFs, see Figure 1, right panel). Spatial frequencies are some of the lowest-level visual features used in perception, providing the basis for processes such as edge detection or texture discrimination. In visual processing, the identification of a stimulus is made possible by re-integration of different SFs, resulting in a characteristic power spectrum, and other higher-order combinations of simple features.

LSFs are preferentially conveyed by the fast-transmitting magnocellular visual channels and activate the anterior half of the calcarine fissures, linked to the peripheral visual field, while HSFs are conveyed by slower-transmitting parvocellular visual channels and activate the posterior part of the occipital lobe, linked to foveal vision. The processing speed difference between magnocellular and parvocellular streams amounts to $10 \mathrm{~ms}$ in typically developing adults but can be as large as $40 \mathrm{~ms}$ ([76], cited in Reference [77]). In line with models of visual recognition [78-80], the well-established coarse-to-fine processing sequence [81] is explained by faster access of the LSFs to higher-order visual areas in the brain's dorsal stream. These areas can, in turn, modulate the subsequent processing of the HSFs, which are transmitted more slowly to the brain's ventral stream.

It is generally accepted that two broad visual streams process information relatively independently. The dorsal stream is concerned with vision for action and the ventral stream is concerned with vision for perception [82]. The dorsal stream is linked to motion processing and visuo-spatial transformation, which is preferably signaled by magnocellular cells and mainly relies on fast processing of low spatial frequencies across the visual field. The function of the ventral stream is linked to processing of color and form, texture, and general object perception, and preferably draws on parvocellular cells, foveal processing, and high spatial frequencies. The division of the visual field into a high acuity fovea driving ventral stream analysis of object details and a low acuity periphery specialized in signaling scene gist [83] and transients for dorsal stream processing has likely evolved to optimize bandwidth and 
energy, and is the main reason for overt attention expressed by eye movements [84]. Peripheral vision selects objects of interest as saccade targets for close inspection by foveal vision. Peripheral selection and foveal inspection occur in parallel, but selection is usually faster than inspection [85].

However, only a few studies have linked the two visual streams to hemispheric asymmetries. Notably, Stevens et al. (2012) [86] discuss a general pattern of right/left asymmetry of form-specific versus form-abstract visual processing, and demonstrate that the left para-hippocampal place area is relatively more involved in form-abstract conceptual/semantic processing of complex visual scenes, while the right para-hippocampal place area is involved in relatively more form-specific perceptual processing. With respect to the function of the dorsal stream, Pisella et al. (2011) [87] reported a right-hemispheric dominance for visual remapping-important for saccade programming, and Sheremata et al. (2010) [88] found that only the right posterior parietal cortex codes visual short-term memory load independent of the visual stimulus, which is consistent with the finding that hemi-spatial neglect, a deficit in contra-lesional attentional processing, which typically involves damage to right-hemisphere parieto-temporal lobes. Stephan et al. (2007) [89] provide neurophysiological evidence for asymmetric information transfer and hemispheric recruitment in ventral and dorsal streams, respectively, during induced task-driven lateralization. Despite these findings, clearly plenty remains to be explored. Taken together, there appears to be some evidence that visuo-spatial cognitive processes primarily drawing on LSF information are right-lateralized, whereas processes related to object semantics and language, primarily relying on HSF information, are left-lateralized.

The complementary processes of frequency analysis and re-integration constitute a multi-modal working principle of the brain. The brain is lateralized not only for spatial but also for temporal frequencies [90-92] since birth [93]. The left brain hemisphere is predominant in extrapolating relatively fine signals and from short time windows (high TFs) while the right brain hemisphere is superior in processing relatively coarse signals and from long time windows (low TFs). Consistent insight for this specialization comes from developmental neuropsychology and, in particular, from Autism Spectrum Disorder. People with autism tend to report a co-morbidity that consists of atypical perception in the visual and in the auditory domains with enhanced ability to process local features [94-96].

\subsection{Hemispheric Lateralization for SF Processing and Previous Models}

Given that global and local processing are associated with a preference for LSF and HSF, respectively, and with the perceptual and behavioral asymmetries we discussed in part 1, it follows that there should also be asymmetries for SF processing. Although the data are consistent with functional asymmetries for SF processing (see Reference [3] for review), current models are inconsistent about the mechanism underlying this hemispheric tuning. Before describing these models, it is important to clarify the experimental tasks in which lateralization emerges. The interactions between hemispheric engagement and SF bands were found in activities characterized by high cognitive demand (e.g., identification, recognition, and copying). Instead, when the tasks had almost exclusively perceptual characteristics (e.g., contrast sensitivity tests, detection, sensory summation), the hemispheres showed comparable $\mathrm{SF}$ tuning [97]. More involvement of the right hemisphere is registered only under high perceptual uncertainty (e.g., perceptually degraded stimuli, see Reference [98] for a review). This implies that SF channels in V1 are symmetric and that processing differences originate beyond the early perceptual level.

Several important, and inter-related, theories regarding the organization of our perceptual processing have emerged in recent decades that considerably reframed older arguments such as those from classical Gestalt psychology. While these modern accounts heavily intersect, they predominantly focus on different ideas about functional lateralization, SF processing biases between the hemispheres, and the emergence of conscious perception. The models we review include Sergent's model [1], the Dual Filtering by Frequency hypothesis (DFF, [90,99], the reverse hierarchy theory of perceptual learning (RHT, [100-102], and the coarse-to-fine processing hypothesis (CTF, [103]). 


\subsubsection{Sergent's Model}

Sergent (1982) [1] postulated that hemispheric sensitivity to different SF bands is symmetric during early stages of processing, becoming asymmetric during later stages. When performance requires higher cognitive effort, the right hemisphere deals more efficiently with LSF content conveyed through the fast magnocellular stream. On the other side, the left hemisphere becomes predominant in processing HSF content, made available later, through the slow parvocellular pathway.

\subsubsection{Dual Filtering by Frequency (DFF)}

The observation that hemispheric asymmetries for SF processing depend on the relative and not absolute SF ranges led Robertson and Ivry [90] (see Reference [99]) to advance the DFF hypothesis. In contrast with Sergent's (1982) [1] original theory, DFF states that even high-cognitive tasks are characterized by a first stage in which SFs processing is symmetric in the brain. In the first stage, low-level sensory information is sent to both hemispheres so that attention filters the SF range most relevantly for the current activity. Only in the second stage, the right/left hemispheres act as asymmetric filters to emphasize the lower/higher SFs, but relative to the initially selected SF band. The DFF theory postulates the presence of dynamic mechanisms between low-level processing by SF channels and high-level attentional selection of these channels [104]. This is well supported by evidence on flexible preference of the same SFs by the different hemispheres, depending on the reference SF range involved in the stimulus set [105].

\subsubsection{Reverse Hierarchy Theory (RHT)}

This theory of perceptual learning originally set out to link the rapid capture of conceptual gist -in the absence of access to its constituent features-with the generalization (or lack thereof) of training effects in perceptual learning tasks [101]. In contrast to the anatomical hierarchy, where vision is assembled from simple cells into increasingly complex and broad receptive fields, the Reverse Hierarchy Theory argues that perception proceeds rapidly and implicitly to high-order summaries before cognitive feedback directs attention to the serial processing of relevant detail in the scene. This framework was later expanded to also encompass auditory perception and broadened to cover conscious perception in general. A key component of this theory is the trade-off between convergent activities (linking several diverse, low-level exemplars to the same high-level category) and divergent activities (assigning highly similar, low-level exemplars to distinct high-level categories). Depending on the specific task driving current perception, the categorization may be accurate enough to enable further higher-level processing and decision-making. Alternatively, serial, attention-driven processing of details in the scene may be desirable. When learning how to optimally solve a new perceptual task (i.e., in perceptual learning), both knowing the correct level of detail to process the stimuli and the depth of this level determine generalizability. The more low-level the details required (needing access to earlier stages of the visual hierarchy), the more difficult the learning, the greater the potential gain, but the less any learning generalizes to other perceptual tasks.

\subsubsection{Coarse-To-Fine Processing (CTF)}

While highly related, the Coarse-to-Fine Processing hypothesis for perception places less emphasis on learning and on the "gist" or high-level representation belonging to a specific category, and, instead, takes a Bayesian approach of gradually refining a representation from coarse to fine. Bayesian approaches encompass both descriptive accounts, discussing how different levels of hierarchy interact, as well as more concrete computational accounts that attempt to lay out an inverted (high-low) competitor to traditional computational accounts of perception (e.g., signal detection theory). For example, the account by Ding and colleagues (2017) [106] examined joint distributions of two judgements (differing in complexity) and found that the best model to describe behaviour reflected visual perception as the retrospective decoding of high-to-low features from visual working memory. 
Like in RHT, low-level details are decoded only when required. However, here, the recall of noisy, less-reliably encoded low-level features is explicitly constrained by memory for higher-level features. Generally, many fluctuations in low-level features will be behaviourally irrelevant, and instead reflect inconsequential events like subtle sway in our posture, changes in lighting conditions, or micro saccades. The higher-level stimulus features (e.g., a person's mouth being in a smile) are more relevant, more categorical, and easier to store in working memory than the precise alignment or the precise shade of their right upper lip. Nevertheless, although differing slightly in interpretation, both the Bayesian CTF hypothesis and the RHT emphasize a global representation being perceived first, which is followed by slower, serial processing of details.

\subsection{Brain's Asymmetric Frequency Tuning (BAFT) as Generalized Account of a Perceptual Processing}

All theoretical models of cortical visual processing sketched above share the assumption that the functional lateralization for SFs processing emerges beyond the sensory level. In other words, both hemispheres are endowed with an equal ability to process all ranges of SFs during early processing stages, but with different efficiency in emphasizing low or high SF information for the creation of a percept that is suitable for the current task. It is reasonable to assume the presence of asymmetric cortical circuits with common components, rather than strictly unilateral components underlying the visual and auditory hemispheric tuning of our brains, especially when we think about its adaptive function for ensuring symmetrical sensory sensitivity and, at the same time, enhancing our capability to perform parallel and distinct computations (see Reference [54] for a review on encoding asymmetry).

It is important to consider that brains are embodied and encode sensory and motor inputs within a body-centred spatial reference frame. According to the recently popular embodied cognition perspective, cognition is supported by modal representations that originate from reciprocal exchanges between the organism and the surrounding environment [107-110]. Embracing and developing this view, the recently proposed brain's asymmetric frequency tuning model [111] treats lateralization for SF processing as a congenital aspect of the mind that influences learning and cognition through interaction with sensory and motor constraints imposed by the body. Which implications does the functional asymmetry driven by SFs have on cognition? BAFT addresses this question and derives testable predictions. We briefly describe the components of the model before explaining its specific contributions within different cognitive domains.

BAFT relies on three fundamental facts that were already established above: (1) The vertebrate brain spontaneously analyses SF information to create a coherent percept and to inform the distinction between vision for perception and vision for action, (2) SF processing is lateralized with the left and right brain hemispheres predominantly selecting high and low SFs, respectively, (3) due to the cross-over of the optic fibers at the level of the optic chiasm (partial in humans and total in animals with laterally located eyes), information from each hemi-field projects to the contralateral hemisphere that, in turn, drives attentional orienting toward the contralateral space. Figure 2 graphically represents the three components of the BAFT model.

Previous models on brain asymmetries for SFs processing have focused on the mechanism underlying the second assumption. Instead, BAFT integrates this mechanism with the hemispheric control of spatial attention (assumption 3), thus, linking the SF tuning principle to spatial biases in behavior. In addition, BAFT considers functional brain asymmetry for frequency processing to be a universal constraint that interacts with embodied and contextual factors, thus, shaping all levels of knowledge representation (for details of this theoretical framework, see References [112-114]). The structure of the visual system, the asymmetry in SF selection, and the asymmetry of attentional orienting, naturally lead to an optimal representation of fine detail in the right visual field and coarse features in the left visual field. BAFT, incorporating this implication, explains several behavioral consequences of these perceptual asymmetries driven by SFs lateralization in different cognitive domains. 

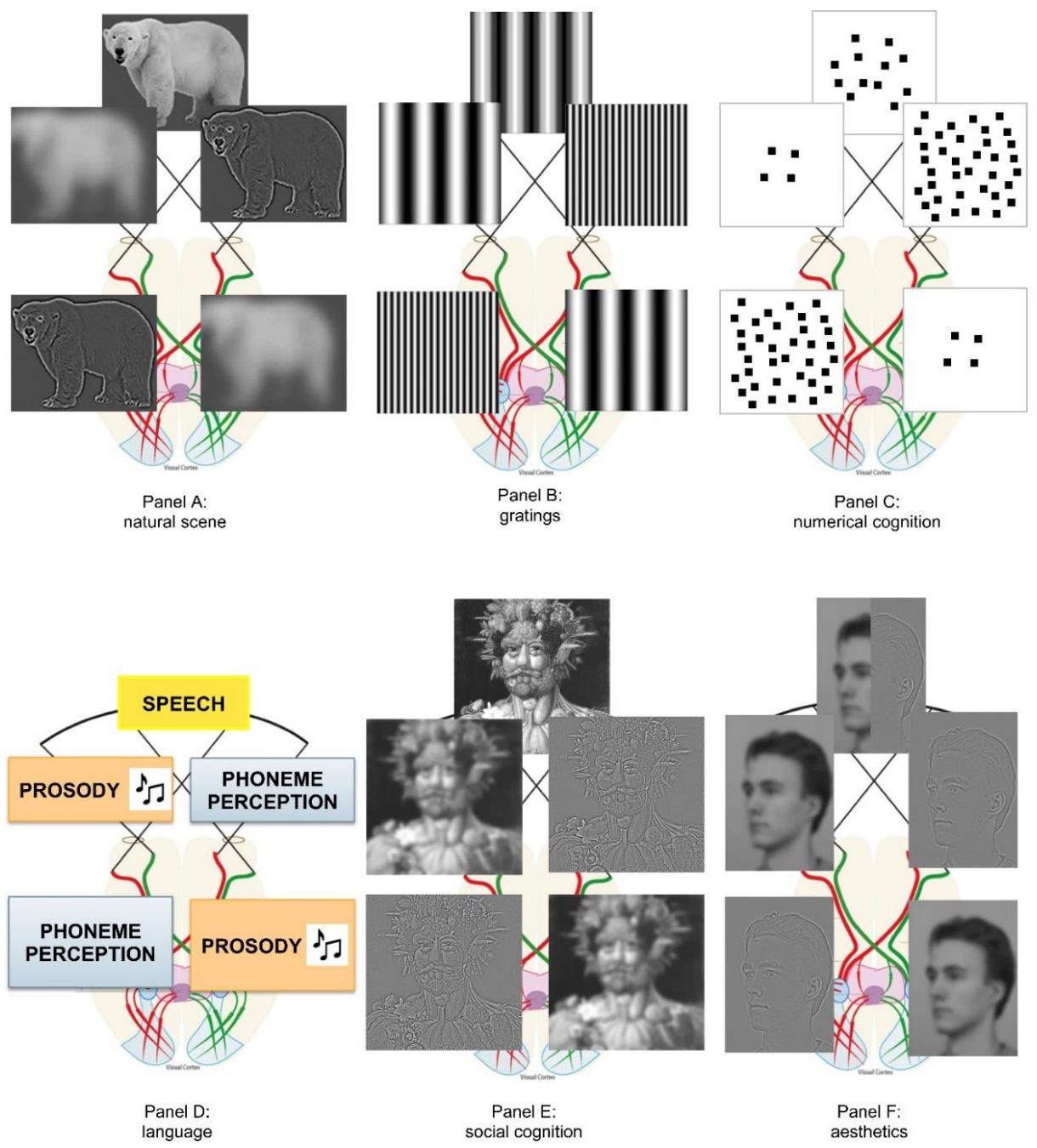

Figure 2. Components and implications of the Brain's Asymmetric Frequency Tuning (BAFT) model. All panels depict the BAFT principle postulating that, for a given percept (top row), the left/right hemisphere preferentially processes the high/low frequencies (bottom row), thus, leading to representation of detail/coarse elements on the right/left hemi-field (middle row), respectively. Panels A,B display applications of the BAFT principle to a visual scene (panel A) and to Spatial Frequency (SF) defined contrast gratings (Panel B), respectively. For a given percept that contains SFs in the middle range, the left/right hemisphere preferentially filters more/less dark and light cycles per degree of the visual angle and entails creation of a high/low SF percept in the contralateral hemi-field. Panels C-F represent implications of BAFT for domains of numerical cognition, language, social cognition, and aesthetics, respectively. They explain and illustrate specific predictions of BAFT: an association of small numerosities with left space and of large numerosities with a right space (Panel C). The left lateralization for high spatial/temporal linguistic features, such as syllable and phoneme processing, and right lateralization for low spatial/temporal modulation of language, such as sentence processing and prosody (Panel D). Hemispheric tuning for local/global processing involved in object/face recognition in ambiguous portraits such as those by Arcimboldo (Panel E), and more attractiveness for faces showing the left-cheek (Panel F). Notes: The polar bear scenes of Panel A are adapted from Figure 3 of Reference [115], licensed under CC-BY, version 4.0. The painting 'Vertumnus' by Guiseppe Arcimboldo of Panel E is filtered from https://commons.wikimedia.org/wiki/File:Vertumnus_årstidernas_gud_målad_av_Giuseppe_ Arcimboldo_1591_-_Skoklosters_slott_-_91503.tiff; public domain. The model's photo of Panel F is filtered and adapted from Figure 1 of Reference [116], licensed under the Copyright Clearance Center. The anatomy of visual pathways is redrawn after Figure 1 of Reference [117], licensed under CC-BY, version 4.0. 


\section{Extending BAFT to Other Cognitive Domains}

In the first part of this paper, we reviewed a wide range of asymmetries in behavior that can be explained as resulting from functional perceptual asymmetries. In the second part, we described several models of asymmetrical perceptual processing that can account for these observations. We ended that second section with the introduction of BAFT, which is a recently developed proposal that relies on the principle of asymmetrical SF processing (see Figure 2, especially panels A and B). Now we explain how BAFT can account for processing biases in higher-level cognitive domains, including numerical cognition, reading difficulties, social interactions, and aesthetic preferences (see Figure 2, panels C-F).

\subsection{Numerical Cognition and Dyscalculia}

Our ability to process and compare quantities is evolutionarily advantageous. Clearly, when the visual angle is constant, then a larger numerosity is related to a higher SF content. Therefore, our first extension of BAFT is to the domain of visual quantities and their asymmetrical processing. In numerical cognition, we distinguish numerosities (i.e., quantities of objects) from numbers (i.e., the symbols denoting these quantities). Asymmetrical spatial-numerical associations (SNAs) were an important discovery, reflecting the ubiquitous tendency to associate numbers with space [118]. This frequently replicated fact has suggested a spatial representation of numerical information along a horizontally oriented mental number line (for review, see Reference [119]). Mapping numbers (as symbolic quantities) onto space is a cognitive strategy shared by all cultures [120] and not restricted to the human kingdom (See Reference [121] for review). Recently, a taxonomy on SNAs has been provided to account for the multi-componential nature of this phenomenon [122]. Different properties of numbers (ordinal, cardinal, place-value, and arithmetic functions) can be, implicitly or explicitly, associated with different aspects of the space (extension or direction). Here, we focus on mapping the cardinal information of numbers (small vs. large) to different spatial directions (left vs. right). While humans may learn this association between number symbols and horizontal space through cultural techniques, the presence of a similar association for non-symbolic numerosities already in human newborns [123] and in animals [124] requires a biological explanation.

The BAFT hypothesis postulates a non-numerical origin of horizontal SNAs by relying on the above-mentioned functional perceptual asymmetries. The typical behavioral bias reported by human newborns and non-human animals, when dealing with non-symbolic numerosities, can be explained by the hemispheric SF processing asymmetry described above. As shown by Felisatti et al. (2020) [111], patterns with few elements, containing more power on low SFs, would preferentially engage the right hemisphere, inducing a left-bias. Conversely, patterns with many elements, containing more power on high SFs, would preferentially engage the left hemisphere, inducing a right bias (see Figure 2, panel C). In addition, there is evidence for non-symbolic SNAs in adults that could reflect the influence of hemispheric spatial frequency tuning [125-127]. Importantly, as in SF processing, what determines the spatial bias is the relative SF range contained in the stimulus of interest with respect to the overall SF range defining the stimulus set $[104,105]$. Furthermore, in numerical cognition, the spatial mapping of numbers is not absolute but depends on the numerical range ([128], Exp. 3, [129]).

BAFT can be extended to other studies of early emerging non-symbolic SNAs. Specifically, Bulf and colleagues (2016) [130] provided evidence of horizontal space-quantity-associations in eight-to-nine-month-old infants by using a detection paradigm where the observers' attention was directed laterally by a cue before measuring the efficiency of sensory registration. Their attentional cue consisted of either non-symbolic numbers (two vs. nine dots) or X-shaped stimuli varying in size (small vs. large). The authors predicted that if small is associated with left and large with right, then small cues (a 2-dot pattern and small letter X) should facilitate detection of left-located target stimuli. Conversely, large cues (a 9-dot pattern and large letter X) should facilitate detection of right-located target stimuli, as reported in adults [131]. While the non-symbolic-number cues corroborated the hypothesis, the X-shaped cues revealed an opposite trend. The authors interpreted their results in terms of an automatic vs. acquired tendency to map numerical vs. non-numerical 
magnitude onto space, respectively. Instead, the BAFT account unfolds the apparently counterintuitive findings in light of SF processing. In addition, 2-dot as well as large X-shaped stimuli contain lower SFs with respect to 9-dot and small X-shaped stimuli, thus, resulting in a leftward bias. Together, the facts that we naturally apply frequency filtering to visual perception, and that this functional filter is shared by a wide range of non-human species, can explain how non-symbolic associations between quantities and space emerge as a result of the evolutionary developed, biological structure of our minds.

\subsection{Language, Dyslexia, and Music}

The notion of functional hemispheric specialization for low vs. high SFs is also an important approach for understanding deficits in the acquisition of reading skills, commonly referred to as Developmental Dyslexia (DD). DD can be defined as the inability to obtain, despite adequate training opportunities, an age-consistent level of reading competence, considering both reading speed and text comprehension. Depending on the specific criteria applied in the assessment of DD, between $5 \%$ and $17 \%$ of children can be considered dyslexic [132]. The condition can be inherited and affects more males than females [133]. Dyslexia is often comorbid with dyscalculia ([134-137], but see Reference [138]). Given that reading is a multi-componential task involving perceptual, cognitive, and oculo-motor processes, it is not easy to determine whether a dyslexia-causing deficit originates with stimulus encoding, or with phonological activation induced by successfully identified graphemes, or as a result of imprecise control over one's eye movements.

Ever more perceptual, language-specific cognitive and motor deficits have been reported in Developmentally Dyslexic children (DDs) over the decades. Although substantial evidence has converged on a phonological (awareness or discrimination) deficit at the core of DD [139,140], more recent studies have identified perceptual limitations as additional and, perhaps, more fundamental contributors to DD. Given our present focus on cognitive signatures induced by functional perceptual processing asymmetries, we selectively report this evidence here.

In his recent review of dyslexia research, Stein (2018) [141] points out that the two brain hemispheres must provide temporally structured input for cognition from all modalities, including stimulation from visual and auditory language. The brain's inability to relay this input in a timely manner seems to be the common denominator for the wide range of performance deficits observed in DDs. The deficit relates to the already-mentioned two neuro-biologically distinct processing pathways in each of the two brain hemispheres, which originate at the retinae and then connect through sub-cortical channels into cortical areas. To remind readers, the magnocellular pathway is characterized by relatively fast processing of coarse visual information feeding dorsal processing streams into the parietal lobes that resolve a spatial detail for action control. This view lines up with the low spatial frequency tuning previously described for right-hemispheric processing. Instead, the parvocellular pathway processes visual detail (i.e., higher spatial frequencies at slower speed, the ventral cortical streams receive a mix of magno-cellular and parvo-cellular input to support attention allocation for object identification (Stein, 2018). In this view, DD can be understood as reflecting a damaged magnocellular pathway that slows down information for all cognition.

In a recent series of experiments, Franceschini and colleagues (2017) [142] provided converging evidence for the view that the normal processing speed advantage of low over high SFs (the previously mentioned "global precedence," [4]) is not present in unselected samples of DDs. They showed instead local precedence, as indicated by interference from local on global visual elements in a task requiring the processing of hierarchical Navon stimuli (see Figure 1 above). This finding was interpreted as evidence for a selective processing deficit along the magnocellular dorsal stream, which is known to be specialized for low spatial frequencies and the provision of information on stimulus locations. The consequence of the resulting relative local precedence is that reading cannot rely on the initial classification of letter strings that normally precedes identification of individual elements (cf. [143]).

Additionally, acoustic information travels along two streams, extending from the cochleae to primary and non-primary auditory cortices. The dorsal pathway is confined to the left hemisphere and 
is responsible for transformation of time-dependent speech signals into a motor format. The ventral pathway is organized more bilaterally and converts complex auditory features (e.g., prosody) into time-invariant speech representations [144,145]. The stronger lateralization and frequency dependency of the dorsal route further supports the prediction of the magnocellular pathway involvement in the impaired perception and motor computation of speech with intact prosody in DD.

In his review, Stein (2018) [141] explains the rationale for identifying the perceptual, timing-related processing deficit of DDs that would extend BAFT: "By exploiting the high contrast sensitivity of magno-cells at low luminances and high temporal frequencies, to which parvo-cells do not respond at all, we can selectively stimulate the subcortical magnocellular system in order to decide whether its impairment impacts on dorsal stream function as a whole" ([141], page 5). Although Skottun (2015) [146] has cautioned against such a strict separability of processing, we believe that the idea of impaired high-speed temporal processing not only explains DD's problems with phonological and discrimination tasks but also the frequent co-morbidity of dyslexia and dyscalculia we mentioned earlier.

The apparent lack of the neuro-typical visual processing succession from global to local visual elements in dyslexics may also be the reason for further correlated cognitive deficits in this population, including attentional deficits, hyperactivity, or learning disabilities [147,148]. An implication of the view of dyslexia as caused by an SF processing imbalance is that this easily measurable encoding anomaly could be incorporated into personalized models of dyslexia, along with orthographic, phonological, and vocabulary knowledge as predictors of an individual's deficit [132].

Language and, especially, language production, is the textbook example of a lateralized brain function, and is usually left-lateralized, as exemplified by the canonical Wernicke-Geschwind model $[52,149,150]$. On the other hand, music is right-lateralized, which might explain why music and math are related (cf. [151]). Since music is a kind of communication, it is possible that the brain tries to keep the two communication systems as distinct as possible. "Amusical" individuals, who cannot sing in tune and often cannot detect out-of-tune melodies, are characterized by abnormalities in neural transmission between the auditory cortex and the inferior frontal gyrus in the right cerebral hemisphere [152]. Disorders of musical pitch occur in relative isolation from speech disorders [153].

Some aspects of music, such as the syntax of complex pieces, however, might be left-lateralized and, thus, be contributed by language-specialized areas, while the processing of most other features, such as pitch and rhythm, is right-lateralized. On the other hand, a few aspects of language processing such as rhythm and sentence-level prosody seem to be contributed by the right hemisphere [154]. This is exploited by "Melodic Intonation Therapy" [155], which is one of a few effective therapies for aphasia, based on the observation that patients can often sing words that they cannot speak. Training the singing of words seems to be effective in recovering language functioning, if only for more or less formulaic speech. Melodic Intonation Therapy also includes rhythmically stroking the left hand, which is intended to activate the right hemisphere.

A recent study sheds some light on how the differential hemispheric specialization to language and music might be related to different sensitivity to spatial and temporal frequencies. Albouy and colleagues (2020) [156] selectively manipulated temporal or spectral features in sung speech. They found that perception of speech decreases only with degradation of temporal information, whereas perception of melodies decreases only with spectral degradation. These results are consistent with observations that the temporal modulation rate found in speech samples from many languages is substantially higher than that of music samples across genres [106].

Again, in terms of BAFT, a high temporal modulation rate might correspond to detailed, local processing, whereas music perception might correspond to more global processing (see Figure 2, panel D). The two parallel systems of communication that humans have developed including one in each hemisphere, and the need to efficiently separate encoding of their respective preferred features, might actually be one of the prime driving forces of the brain's top-down modulation of frequency tuning. 


\subsection{Social Cognition and Emotion}

Humans, like most animals, are inherently social and devote considerable neural resources to the identification, understanding, and prediction of the emotional and cognitive states of others. This capability encompasses a wide variety of different mental tasks from the basic perception of social cues to complex social learning and mimicry [157]. The mechanisms underlying social cognition include highly specialized processes that are seemingly developed specifically to support social interactions (e.g., dedicated cortical face processing areas) as well as more general cognitive areas in supporting roles (e.g., attentional cueing mechanisms). The network of regions with seemingly dedicated social functions, the "social brain," involves many distinct cortical and subcortical regions throughout the brain [158]. Several of these social functions exhibit not only some degree of hemispheric lateralization but also a special sensitivity to particular SF bands.

The detection, identification, and processing of face stimuli are important for many aspects of social cognition. Both the left and right fusiform gyri show a preference for face stimuli over non-face stimuli, albeit with strong activity typically found in the right $[159,160]$. However, more detailed studies with carefully controlled stimuli suggest a qualitative difference in the type of face information that is the focus of each hemisphere. In a detailed fMRI examination of face processing using both real faces and exceedingly face-like and non-face objects, Meng and colleagues (2012) [161] identified several systematic differences between the two hemispheres. Specifically, they noted that the activity of the left fusiform gyrus was faster and more influenced (with either inhibition or facilitation) by context than the slower, context agnostic activity of the right fusiform gyrus. Interestingly, while activity in the left hemisphere appeared to represent a more image-like representation, activity in the right hemisphere was closely correlated with the categorical decision of whether the stimulus was a face or non-face. Together, these findings were consistent with the left gyrus, representing a detail-focused representation of the stimulus and the right gyrus representing a more abstract representation.

In support of hemispheric tuning for local/global features involved in object/face processing, some studies considered the ambiguous portraits painted by Giuseppe Arcimboldo (see Figure 2, panel E). They deal with hierarchical stimuli reflecting single big faces when processed holistically, or many little objects when processed analytically. Caharel and colleagues (2013) [162] found that Arcimboldo stimuli elicited an N170 signal, which is an electrical signal of the brain that is sensitive to properties of faces. Its amplitude was comparable to faces over the right hemisphere but comparable to objects over the left hemisphere. Moreover, in 7-month-old to 8-month-old infants, Arcimboldo portraits are already recognized as faces but, unlike normal faces, they correlate with neural activity in the left hemisphere due to feature-driven elaboration [163].

Furthermore, face processing is known to be highly influenced by the spatial frequency information available [164,165]. A prominent theory of face processing, the Dual-route model [166], proposes that two interconnected pathways-one cortical and one subcortical-are critical to our face perception. The rapid, subcortical pathway is thought to operate on predominantly LSF information and enables rapid face classification subserving behavior, while the slower cortical pathway, modulated by the faster subcortical inputs, conveys mainly HSF facial information $[167,168]$. Thus, although not containing explicit hemispherical segmentation, the Dual-route model proposes a similar two-step process with rapid LSF processing preceding and influencing the detailed processing of HSF information. When both the detailed methodological studies on hemispherical differences and the spatial frequency findings are considered together, they align closely with the proposal outlined in BAFT.

Hemispherical differences also appear to play a role in emotion processing. Emotional facial expressions presented in the left visual field appear to be perceived more intensely than those in the right visual field [169], suggesting a right-brain dominance for general emotion processing [170]. However, there remains much debate about the origin of this lateralization. While the right hemisphere hypothesis suggests the right hemisphere specializes in general emotional processing [171], the valence hypothesis suggests that the right hemisphere processes negative emotions while the left hemisphere processes positive emotions [172,173]. Both have received support in the literature, depending on 
the paradigm and stimuli chosen, alongside more cognitive explanations in which the difference in hemispherical activity is interpreted as approach/avoidance or behavior activation/inactivation [174].

\subsection{Aesthetics}

Our hypothesis/assumption of functional asymmetry for the processing of SFs can easily be applied to account for some intriguing horizontal asymmetries in the domain of aesthetic preferences. Although mankind's interest in art is ancient, as is the aesthetic interest in symmetry, only more recently systematic spatial aesthetic biases were reported both at the perceptual level of aesthetic appreciation and at the behavioral level of aesthetic preferences.

Several comprehensive surveys of painted portraits found a tendency to paint the left cheek rather than the right one ([175-178], for review, see Reference [179]). Corresponding rightward head-turning biases, revealing one's left cheek to others, were found when participants posed for a portrait in an emotional context, in photography composition [180-183], when rating mirrored portraits [184], and, with clear preference for right-facing objects rather than left-facing ones [183,185]. Recently, Park, Spense, Ishii, and Togawa (2020) [116] reported that left-oriented faces were perceived as more attractive than right-oriented faces, even when stimuli were identical. The authors found the perceived prototypicality as the mediator but a closer inspection may identify in the brain's asymmetric frequency tuning the mechanism underlying apparently dissociable phenomena related to left-oriented faces: more fixations [186], ease of recognition [187], prototypicality, and attractiveness [116].

Nevertheless, the accumulated evidence for gender differences [188], a possible change of bias over the life span [189], the mood-dependency of aesthetic preferences [190-193], and the involvement of culturally acquired techniques, such as reading direction in aesthetic preferences ([194-197], for review see Reference [198]) all indicate against a simple explanation, such as innate asymmetry of hemisphere specialization. However, and although speculative, it may be the case that aesthetic preferences for portrait directionality, as well as for horizontal-facing objects, are also partially influenced by the brain's asymmetric frequency tuning (see Figure 2, panel F).

Our hypothesis calls for revisiting some other well-established horizontal perceptual asymmetries. For example, various asymmetries in spatial composition were found, such as:

(a) a preference to place content of greater interest ('weight') on the right compared to the left side (the Right Bias), at least in right-handed participants [199,200],

(b) similar asymmetrical spatial preferences for larger salient content on the right side of paintings [199],

(c) the scanning motion bias, according to which we tend to scan our perceptual field left-to-right [201, 202], which is in accordance with a preference for stimuli with left-to-right directionality [203]. Moreover, Maass, Pagani, and Berta (2007) [204] found that left-to-right readers rated movie clips of lateral actions as stronger, faster, and more beautiful when actions had left-to-right directionality, while right-to-left readers showed the reverse pattern (see Reference [205]),

(d) a leftward attractiveness bias, according to which participants judge the left side of abstract visual patterns as more attractive than the right side [206].

The lack of comprehensive cross-cultural studies makes it hard to decide the possibility of a biological origin of these effects. The current results from cross-cultural studies seem to favor a view that the aesthetic preference bias is grounded in hemispheric specialization, but its strength is modulated by learned scanning habits such as reading direction [205].

\section{Implications and Outstanding Questions-Experimental Avenues}

It is clear that human behavior consists of a wide range of asymmetrical activities that span the perceptual, cognitive, and motor domains. We have previously reviewed the empirical evidence and described theoretical accounts for asymmetric signatures. One main message was that the idea of spatial frequency tuning of the brain's hemispheres can be considered as a broad principle from which 
most of these asymmetries can be explained. Moreover, the same principle can be extended to also cover a higher level of cognitive biases. In this final section, we make some suggestions for future research that could help to develop our proposal further.

Consider first the visual processing. The majority of literature focuses on what happens at fixation. However, humans presumably spend considerable time attending to objects in their visual periphery through covert attention, e.g., to plan forthcoming eye movements that target objects of detailed interest. Given the SF tuning of the two hemispheres and resulting asymmetry, peripheral signals will be differentially represented when located in the left vs. right hemifield. This has implications for reading research and scene perception studies, where our understanding of the use of parafoveal previews can distinguish between competing models (cf. [85,207-213]). It also affects our everyday life, ranging from design decisions for classroom setups (where emotions are differently interpreted by different hemispheres) to driving regulations (where obstacles must be processed and responded to) and to aesthetic judgement and marketing communication (where spatial orientation influences product evaluation).

Now, consider the foundational domain of numerical cognition. According to the BAFT hypothesis, the functional link between SF processing and space-quantity associations described previously could predict the link between impaired number acuity (i.e., the ability to discriminate visual numerosities) and the propensity to develop dyscalculia, which is a developmental disability affecting numerical and mathematical learning [214]. Dyscalculia might be the anatomical expression of asymmetric inhibitory control between the two brain hemispheres [44,45].

An informative experiment would consist of manipulating the SF content of numerical stimuli. Furthermore, if functional lateralization for SF processing establishes our tendency to map numbers onto space, it would be expected that, in healthy infants, but not in developmental dyscalculics, spatial-numerical associations will emerge, even when using different SF contents for the same number.

Given the large heterogeneity in lateralization in the population, this has implications for how individuals may vary. Future work should measure differences in anatomical and functional lateralization and see how this predicts performance in numerical vs. non-numerical tasks. Particularly, the diagnostic would also be a consideration of brain lateralization, and of the BAFT mechanism in particular, in artificial neural network models. Computational modelling has already provided evidence in support of an emergentist perspective, according to which our intuitive number sense would originate from contributions by evolutionary and learning constraints on perception and cognition [215].

BAFT can also be extended to the auditory perceptual domain, motivated by the following considerations. First, there is a close analogy between visual and auditory signal decomposition into frequency components (Fourier analysis). Second, a similar analogy exists between the functional asymmetric frequency processing of visual and auditory stimuli [92,93]. As a consequence, in analogy to the hemispheric spatial frequency tuning for visual stimuli, a hemispheric temporal frequency tuning could be expected for auditory stimuli. This view offers a re-interpretation of the findings reported by de Hevia and colleagues (2017) [216]. Human infants exhibit leftward/rightward behavioral biases after presentation of a few/many syllables, respectively. Specifically, for a given overall duration, few syllables are conveyed through lower temporal frequencies with respect to many syllables, thus, resulting in more engagement of the right hemisphere and leftward behavioral bias (see Reference [216], Experiment 4). Instead, when syllable durations remain constant, presenting few syllables after familiarization with many syllables triggers fine-to-coarse processing and involves the right hemisphere preferentially, with consequent leftward behavioral bias (see Reference [216], Experiment 5).

A final domain of study where we expect valuable insights through the BAFT perspective is neuropsychology with a focus on rehabilitation procedures. Specifically, it may be possible to reduce the impact of cortical damage by careful design and presentation of SF-filtered stimuli. Especially with the emergence of AR and VR devices, where stimuli can be preferentially presented to specific eyes, this could be used to try to drive processing toward the desirable hemisphere for different tasks. 
However, before BAFT can be applied, certain challenges have to be addressed. For instance, usually the task to assess spatial attention biases is the landmark task, in which subjects have to indicate whether a line is transected to the left or right of its midpoint. Recent work looking at a variety of different spatial bias measures (see Reference [217]) demonstrated a profound (and replicated) lack of inter-task correlations. This suggests that these different measures of spatial attention bias are themselves tapping into different mechanisms. Notably, these tasks differ in how they utilize spatial frequency information alongside attentional biases. The spatial attentional biases most relevant to the BAFT theory are those in which there is competition for attention allocation to either the left or right visual field. With regard to the various implications of BAFT that we outlined (be it numerosity or aesthetic judgements), these are situations in which there is competition of the allocation of attention to the left or right visual field. The efficiency with which different information (at different spatial frequencies) is processed in the left and right hemifield will influence their relative salience and the biasing in orientating behaviour. This effect may be further supplemented by generalized spatial attention biases (see Reference [17]). However, with more complex stimuli (beyond a simple uniform line) that convey different (when images that are not horizontally mirrored) information at multiple different spatial frequencies, hemispherical competition in spatial orientating is much more subject to the saliency of image and its spatial frequency properties.

In conclusion, the BAFT hypothesis does not argue for an exclusive role of evolutionary predisposition to perceptual, cognitive, and motor spatial biases. As we already discussed above, recently accumulated evidence highlights the contributions of both embodied cultural habits and situated experiences to behavioral spatial asymmetries. We call for revisiting previously found asymmetric behavior in various domains, considering brain asymmetric frequency tuning, which can be later shaped by spatial habits and recent temporary events.

Author Contributions: Conceptualization, A.F., D.A.-M. and M.H.F.; writing-original draft preparation, A.F., D.A.-M., J.L., S.S., M.H.F.; writing-review and editing, A.F., D.A.-M., J.L., S.S., M.H.F.; supervision, M.H.F.; funding acquisition, A.F. and M.H.F. All authors have read and agreed to the published version of the manuscript.

Funding: AF and MHF acknowledge grant support through DFG-FI-1915/8-1 “Competing heuristics and biases in mental arithmetic."

Conflicts of Interest: The authors declare no conflict of interest.

$\begin{array}{ll}\text { Abbreviations } \\ \text { BAFT } & \text { Brain's Asymmetric Frequency Tuning } \\ \text { CTF } & \text { Coarse-To-Fine } \\ \text { DD } & \text { Developmental Dyslexia } \\ \text { DDs } & \text { Developmental Dyslexics } \\ \text { DFF } & \text { Dual Filtering by Frequency } \\ \text { HSFs } & \text { High Spatial Frequencies } \\ \text { LSFs } & \text { Low Spatial Frequencies } \\ \text { RHT } & \text { Reverse Hierarchy Theory } \\ \text { SFs } & \text { Spatial Frequencies } \\ \text { SNAs } & \text { Spatial Numerical Associations } \\ \text { TFs } & \text { Temporal Frequencies }\end{array}$

\section{References}

1. Sergent, J. The cerebral balance of power: Confrontation or cooperation? J. Exp. Psychol. Human Percept. Perform. 1982, 8, 253-272. [CrossRef]

2. Hellige, J.B. Hemispheric asymmetry for visual information processing. Acta Neurobiol. Exp. 1969, 56, 485-497.

3. Kauffmann, L.; Ramanoël, S.; Peyrin, C. The neural bases of spatial frequency processing during scene perception. Front. Integr. Neurosci. 2014, 8. [CrossRef] [PubMed]

4. Navon, D. Forest before trees: The precedence of global features in visual perception. Cogn. Psychol. 1977, 9, 353-383. [CrossRef] 
5. Van Kleeck, M.H. Hemispheric differences in global versus local processing of hierarchical visual stimuli by normal subjects: New data and a meta-analysis of previous studies. Neuropsychologia 1989, 27, 1165-1178. [CrossRef]

6. Sergent, J.; Hellige, J.B. Role of input factors in visual-field asymmetries. Brain Cogn. 1986, 5, $174-199$. [CrossRef]

7. Kitterle, F.L.; Christman, S.; Hellige, J.B. Hemispheric differences are found in the identification, but not the detection, of low versus high spatial frequencies. Percept. Psychophys. 1990, 48, 297-306. [CrossRef]

8. Christman, S.; Kitterle, F.L.; Hellige, J. Hemispheric asymmetry in the processing of absolute versus relative spatial frequency. Brain Cogn. 1991, 16, 62-73. [CrossRef]

9. Peyrin, C.; Chauvin, A.; Chokron, S.; Marendaz, C. Hemispheric specialization for spatial frequency processing in the analysis of natural scenes. Brain Cogn. 2003, 53, 278-282. [CrossRef]

10. Peyrin, C.; Chokron, S.; Guyader, N.; Gout, O.; Moret, J.; Marendaz, C. Neural correlates of spatial frequency processing: A neuropsychological approach. Brain Res. 2006, 1073-1074, 1-10. [CrossRef] [PubMed]

11. Piazza, E.A.; Silver, M.A. Persistent Hemispheric Differences in the Perceptual Selection of Spatial Frequencies. J. Cogn. Neurosci. 2014, 26, 2021-2027. [CrossRef] [PubMed]

12. Guiard, Y. Asymmetric Division of Labor in Human Skilled Bimanual Action: The Kinematic Chain as a Model. J. Mot. Behav. 1987, 19, 486-517. [CrossRef] [PubMed]

13. Stanković, M.; Nešić, M. Contralateral Hemisphere Activation by Unilateral Hand Contraction: ReExamining of Global and Local Attention. Percept. Mot. Ski. 2018. [CrossRef] [PubMed]

14. Behrmann, M.; Plaut, D.C. A vision of graded hemispheric specialization: Graded hemispheric specialization. Ann. N. Y. Acad. Sci. 2015, 1359, 30-46. [CrossRef]

15. Brederoo, S.G.; Nieuwenstein, M.R.; Cornelissen, F.W.; Lorist, M.M. Reproducibility of visual-field asymmetries: Nine replication studies investigating lateralization of visual information processing. Cortex 2019, 111, 100-126. [CrossRef]

16. Vingerhoets, G. Phenotypes in hemispheric functional segregation? Perspectives and challenges. Phys. Life Rev. 2019, 30, 1-18. [CrossRef]

17. Brederoo, S.G.; Van der Haegen, L.; Brysbaert, M.; Nieuwenstein, M.R.; Cornelissen, F.W.; Lorist, M.M. Towards a unified understanding of lateralized vision: A large-scale study investigating principles governing patterns of lateralization using a heterogeneous sample. Cortex 2020, 133, 201-214. [CrossRef]

18. Ventura, P.; Delgado, J.; Ferreira, M.; Farinha-Fernandes, A.; Guerreiro, J.C.; Faustino, B.; Leite, I.; Wong, A.C.-N. Hemispheric asymmetry in holistic processing of words. Laterality Asymmetries Body Brain Cogn. 2019, 24, 98-112. [CrossRef]

19. Dundas, E.M.; Plaut, D.C.; Behrmann, M. Variable Left-hemisphere Language and Orthographic Lateralization Reduces Right-hemisphere Face Lateralization. J. Cogn. Neurosci. 2015, 27, 913-925. [CrossRef]

20. Karlsson, E.M.; Johnstone, L.T.; Carey, D.P. The depth and breadth of multiple perceptual asymmetries in right handers and non-right handers. Laterality Asymmetries Body Brain Cogn. 2019, 24, 707-739. [CrossRef]

21. Gerrits, R.; Van der Haegen, L.; Brysbaert, M.; Vingerhoets, G. Laterality for recognizing written words and faces in the fusiform gyrus covaries with language dominance. Cortex 2019, 117, 196-204. [CrossRef] [PubMed]

22. Gerrits, R.; Verhelst, H.; Vingerhoets, G. Mirrored brain organization: Statistical anomaly or reversal of hemispheric functional segregation bias? Proc. Natl. Acad. Sci. USA 2020, 117, 14057-14065. [CrossRef] [PubMed]

23. Jewell, G.; McCourt, M.E. Pseudoneglect: A review and meta-analysis of performance factors in line bisection tasks. Neuropsychologia 2000, 38, 93-110. [CrossRef]

24. Fischer, M.H. Cognition in the bisection task. Trends Cogn. Sci. 2001, 5, 460-462. [CrossRef]

25. Fischer, M.H. Bisection performance indicates spatial word representation. Cogn. Brain Res. 1996, 4, $163-170$. [CrossRef]

26. Fischer, M.H. Word Centre is Misperceived. Perception 2000, 29, 337-354. [CrossRef] [PubMed]

27. Fischer, M. Orthographic contributions to perceived word center. Brain Lang. 2004, 88, 321-330. [CrossRef]

28. Fischer, M.H. Number processing induces spatial performance biases. Neurology 2001, 57, 822-826. [CrossRef]

29. Girelli, L.; Marinelli, C.V.; Grossi, G.; Arduino, L.S. Cultural and biological factors modulate spatial biases over development. Laterality Asymmetries Body Brain Cogn. 2017, 22, 725-739. [CrossRef] 
30. Rinaldi, L.; Di Luca, S.; Henik, A.; Girelli, L. Reading direction shifts visuospatial attention: An Interactive Account of attentional biases. Acta Psychol. 2014, 151, 98-105. [CrossRef]

31. Maass, A.; Suitner, C.; Nadhmi, F. What drives the spatial agency bias? An Italian-Malagasy-Arabic comparison study. J. Exp. Psychol. Gen. 2014, 143, 991-996. [CrossRef] [PubMed]

32. Rosenich, E.; Shaki, S.; Loetscher, T. Unstable world: Recent experience affects spatial perception. Psychon. Bull. Rev. 2020, 27, 286-292. [CrossRef] [PubMed]

33. McManus, I.C.; Edmondson, D.; Rodger, J. Balance in pictures. Br. J. Psychol. 1985, 76, 311-324. [CrossRef]

34. Robertson, L.C.; Lamb, M.R. Neuropsychological contributions to theories of part/whole organization. Cogn. Psychol. 1991, 23, 299-330. [CrossRef]

35. Bowers, D.; Heilman, K.M. Pseudoneglect: Effects of hemispace on a tactile line bisection task. Neuropsychologia 1980, 18, 491-498. [CrossRef]

36. Cazzoli, D.; Chechlacz, M. A matter of hand: Causal links between hand dominance, structural organization of fronto-parietal attention networks, and variability in behavioural responses to transcranial magnetic stimulation. Cortex 2017, 86, 230-246. [CrossRef]

37. Thiebaut de Schotten, M.; Dell'Acqua, F.; Forkel, S.; Simmons, A.; Vergani, F.; Murphy, D.G.M.; Catani, M. A Lateralized Brain Network for Visuo-Spatial Attention. Nat. Prec. 2011. [CrossRef]

38. Dos Santos, N.A.; Andrade, S.M.; Fernandez Calvo, B. Detection of spatial frequency in brain-damaged patients: Influence of hemispheric asymmetries and hemineglect. Front. Hum. Neurosci. 2013, 7. [CrossRef]

39. Chechlacz, M.; Mantini, D.; Gillebert, C.R.; Humphreys, G.W. Asymmetrical white matter networks for attending to global versus local features. Cortex 2015, 72, 54-64. [CrossRef]

40. Berardi, N.; Bodis-Wollner, I.; Fiorentini, A.; Giuffré, G.; Morelli, M. Electrophysiological evidence for interhemispheric transmission of visual information in man. J. Physiol. 1989, 411, 207-225. [CrossRef]

41. Nowicka, A.; Grabowska, A.; Fersten, E. Interhemispheric transmission of information and functional asymmetry of the human brain. Neuropsychologia 1996, 34, 147-151. [CrossRef]

42. Robertson, L.C.; Lamb, M.R.; Zaidel, E. Interhemispheric relations in processing hierarchical patterns: Evidence from normal and commissurotomized subjects. Neuropsychology 1993, 7, 325-342. [CrossRef]

43. Kleinman, J.T.; Gupta, A. The Right Hand Draws the Trees, But the Left Draws the Forest? Behav. Neurol. 2008, 20, 55-60. [CrossRef] [PubMed]

44. Putnam, M.C.; Steven, M.S.; Doron, K.W.; Riggall, A.C.; Gazzaniga, M.S. Cortical Projection Topography of the Human Splenium: Hemispheric Asymmetry and Individual Differences. J. Cogn. Neurosci. 2010, 22, 1662-1669. [CrossRef]

45. Koch, G.; Cercignani, M.; Bonni, S.; Giacobbe, V.; Bucchi, G.; Versace, V.; Caltagirone, C.; Bozzali, M. Asymmetry of Parietal Interhemispheric Connections in Humans. J. Neurosci. 2011, 31, 8967-8975. [CrossRef]

46. Warrington, E.K.; Broadbent, D.E.; Weiskrantz, L. Neuropsychological studies of object recognition. Philos. Trans. R. Soc. Lond. B Biol. Sci. 1982, 298, 15-33. [CrossRef]

47. Damasio, A.R. Prosopagnosia. Trends Neurosci. 1985, 8, 132-135. [CrossRef]

48. Farah, M.J. Cognitive Neuropsychology: Patterns of Co-occurrence Among the Associative Agnosias: Implications for Visual Object Representation. Cogn. Neuropsychol. 1991, 8, 1-19. [CrossRef]

49. Musel, B.; Bordier, C.; Dojat, M.; Pichat, C.; Chokron, S.; Le Bas, J.-F.; Peyrin, C. Retinotopic and Lateralized Processing of Spatial Frequencies in Human Visual Cortex during Scene Categorization. J. Cogn. Neurosci. 2013, 25, 1315-1331. [CrossRef]

50. Woodhead, Z.V.J.; Wise, R.J.S.; Sereno, M.; Leech, R. Dissociation of Sensitivity to Spatial Frequency in Word and Face Preferential Areas of the Fusiform Gyrus. Cereb. Cortex 2011, 21, 2307-2312. [CrossRef]

51. Ocklenburg, S.; Güntürkün, O. Hemispheric Asymmetries: The Comparative View. Front. Psychol. $2012,3$. [CrossRef] [PubMed]

52. Corballis, M.C. What's left in language? Beyond the classical model: What's left in language? Ann. N. Y. Acad. Sci. 2015, 1359, 14-29. [CrossRef] [PubMed]

53. Vogel, J.J.; Bowers, C.A.; Vogel, D.S. Cerebral lateralization of spatial abilities: A meta-analysis. Brain Cogn. 2003, 52, 197-204. [CrossRef]

54. Concha, M.L.; Bianco, I.H.; Wilson, S.W. Encoding asymmetry within neural circuits. Nat. Rev. Neurosci. 2012, 13, 832-843. [CrossRef] [PubMed]

55. Rogers, L.J. A Matter of Degree: Strength of Brain Asymmetry and Behaviour. Symmetry 2017, 9, 57. [CrossRef] 
56. Karenina, K.; Giljov, A.; Ivkovich, T.; Malashichev, Y. Evidence for the perceptual origin of right-sided feeding biases in cetaceans. Anim. Cogn. 2016, 19, 239-243. [CrossRef] [PubMed]

57. Robins, A.; Rogers, L.J. Lateralized prey-catching responses in the cane toad, Bufo marinus: Analysis of complex visual stimuli. Anim. Behav. 2004, 68, 767-775. [CrossRef]

58. Andrew, R.J.; Tommasi, L.; Ford, N. Motor Control by Vision and the Evolution of Cerebral Lateralization. Brain Lang. 2000, 73, 220-235. [CrossRef]

59. Rogers, L.J. Lateralization in vertebrates: Its early evolution, general pattern, and development. In Advances in the Study of Behavior; Elsevier: Amsterdam, The Netherlands, 2002; Volume 31, pp. 107-161, ISBN 978-0-12-004531-0.

60. Vallortigara, G. The evolutionary psychology of left and right: Costs and benefits of lateralization. Dev. Psychobiol. 2006, 48, 418-427. [CrossRef]

61. Koboroff, A.; Kaplan, G.; Rogers, L.J. Hemispheric specialization in Australian magpies (Gymnorhina tibicen) shown as eye preferences during response to a predator. Brain Res. Bull. 2008, 76, 304-306. [CrossRef]

62. Sovrano, V.A. Visual lateralization in response to familiar and unfamiliar stimuli in fish. Behav. Brain Res. 2004, 152, 385-391. [CrossRef] [PubMed]

63. MacNeilage, P.F.; Rogers, L.J.; Vallortigara, G. Origins of the left \& right brain. Sci. Am. 2009, 301, 60-67. [PubMed]

64. Vallortigara, G.; Chiandetti, C.; Sovrano, V.A. Brain asymmetry (animal): Brain asymmetry. WIREs Cogn. Sci. 2011, 2, 146-157. [CrossRef] [PubMed]

65. Vallortigara, G.; Rogers, L.J. Survival with an asymmetrical brain: Advantages and disadvantages of cerebral lateralization. Behav. Brain Sci. 2005, 28, 575-589. [CrossRef]

66. Güntürkün, O.; Diekamp, B.; Manns, M.; Nottelmann, F.; Prior, H.; Schwarz, A.; Skiba, M. Asymmetry pays: Visual lateralization improves discrimination success in pigeons. Curr. Biol. 2000, 10, 1079-1081. [CrossRef]

67. Rogers, L.J.; Zucca, P.; Vallortigara, G. Advantages of having a lateralized brain. Proc. R. Soc. Lond. B 2004, 271, S420-S422. [CrossRef]

68. Rezvani, Z.; Katanforoush, A.; Pouretemad, H. Global precedence changes by environment: A systematic review and meta-analysis on effect of perceptual field variables on global-local visual processing. Atten. Percept. Psychophys. 2020, 82, 2348-2359. [CrossRef]

69. Campbell, F.W.; Maffei, L. Contrast and Spatial Frequency. Sci. Am. 1974, 231, 106-115. [CrossRef]

70. Lamb, M.R.; Yund, E.W. The role of spatial frequency in the processing of hierarchically organized stimuli. Percept. Psychophys. 1993, 54, 773-784. [CrossRef]

71. Shulman, G.L.; Sullivan, M.A.; Gish, K.; Sakoda, W.J. The Role of Spatial-Frequency Channels in the Perception of Local and Global Structure. Perception 1986, 15, 259-273. [CrossRef]

72. Shulman, G.L.; Wilson, J. Spatial Frequency and Selective Attention to Local and Global Information. Perception 1987, 16, 89-101. [CrossRef] [PubMed]

73. LeCun, Y.; Boser, B.; Denker, J.S.; Henderson, D.; Howard, R.E.; Hubbard, W.; Jackel, L.D. Backpropagation Applied to Handwritten Zip Code Recognition. Neural Comput. 1989, 1, 541-551. [CrossRef]

74. LeCun, Y.; Bengio, Y.; Hinton, G. Deep learning. Nature 2015, 521, 436-444. [CrossRef] [PubMed]

75. Yamins, D.L.K.; Hong, H.; Cadieu, C.F.; Solomon, E.A.; Seibert, D.; DiCarlo, J.J. Performance-optimized hierarchical models predict neural responses in higher visual cortex. Proc. Natl. Acad. Sci. USA 2014, 111, 8619-8624. [CrossRef]

76. Dreher, B.; Fukada, Y.; Rodieck, R.W. Identification, classification and anatomical segregation of cells with $\mathrm{X}$-like and Y-like properties in the lateral geniculate nucleus of old-world primates. J. Physiol. 1976, 258, 433-452. [CrossRef]

77. Lawton, T.; Shelley-Tremblay, J. Training on Movement Figure-Ground Discrimination Remediates Low-Level Visual Timing Deficits in the Dorsal Stream, Improving High-Level Cognitive Functioning, Including Attention, Reading Fluency, and Working Memory. Front. Hum. Neurosci. 2017, 11, 236. [CrossRef]

78. Bullier, J. Integrated model of visual processing. Brain Res. Rev. 2001, 36, 96-107. [CrossRef]

79. Bar, M. A Cortical Mechanism for Triggering Top-Down Facilitation in Visual Object Recognition. J. Cogn. Neurosci. 2003, 15, 600-609. [CrossRef]

80. Peyrin, C.; Michel, C.M.; Schwartz, S.; Thut, G.; Seghier, M.; Landis, T.; Marendaz, C.; Vuilleumier, P. The Neural Substrates and Timing of Top-Down Processes during Coarse-to-Fine Categorization of Visual Scenes: A Combined fMRI and ERP Study. J. Cogn. Neurosci. 2010, 22, 2768-2780. [CrossRef] 
81. Musel, B.; Kauffmann, L.; Ramanoël, S.; Giavarini, C.; Guyader, N.; Chauvin, A.; Peyrin, C. Coarse-to-fine Categorization of Visual Scenes in Scene-selective Cortex. J. Cogn. Neurosci. 2014, 26, 2287-2297. [CrossRef]

82. Goodale, M.A.; Milner, A.D. Separate visual pathways for perception and action. Trends Neurosci. 1992, 15, 20-25. [CrossRef]

83. Larson, A.M.; Loschky, L.C. The contributions of central versus peripheral vision to scene gist recognition. J. Vis. 2009, 9. [CrossRef] [PubMed]

84. Findlay, J.M.; Gilchrist, I.D. Active Vision: The Psychology of Looking and Seeing; Oxford University Press: Oxford, UK, 2003; ISBN 978-0-19-852479-3.

85. Laubrock, J.; Cajar, A.; Engbert, R. Control of fixation duration during scene viewing by interaction of foveal and peripheral processing. J. Vis. 2013, 13, 11. [CrossRef] [PubMed]

86. Stevens, W.D.; Kahn, I.; Wig, G.S.; Schacter, D.L. Hemispheric Asymmetry of Visual Scene Processing in the Human Brain: Evidence from Repetition Priming and Intrinsic Activity. Cereb. Cortex 2012, 22, 1935-1949. [CrossRef] [PubMed]

87. Pisella, L.; Alahyane, N.; Blangero, A.; Thery, F.; Blanc, S.; Pelisson, D. Right-hemispheric dominance for visual remapping in humans. Phil. Trans. R. Soc. B 2011, 366, 572-585. [CrossRef]

88. Sheremata, S.L.; Bettencourt, K.C.; Somers, D.C. Hemispheric Asymmetry in Visuotopic Posterior Parietal Cortex Emerges with Visual Short-Term Memory Load. J. Neurosci. 2010, 30, 12581-12588. [CrossRef]

89. Stephan, K.E.; Marshall, J.C.; Penny, W.D.; Friston, K.J.; Fink, G.R. Interhemispheric Integration of Visual Processing during Task-Driven Lateralization. J. Neurosci. 2007, 27, 3512-3522. [CrossRef]

90. Robertson, L.C.; Ivry, R. Hemispheric Asymmetries: Attention to Visual and Auditory Primitives. Curr. Dir. Psychol. Sci. 2000, 9, 59-63. [CrossRef]

91. Poeppel, D. The analysis of speech in different temporal integration windows: Cerebral lateralization as 'asymmetric sampling in time'. Speech Commun. 2003, 41, 245-255. [CrossRef]

92. Flinker, A.; Doyle, W.K.; Mehta, A.D.; Devinsky, O.; Poeppel, D. Spectrotemporal modulation provides a unifying framework for auditory cortical asymmetries. Nat. Hum. Behav. 2019, 3, 393-405. [CrossRef]

93. Telkemeyer, S.; Rossi, S.; Koch, S.P.; Nierhaus, T.; Steinbrink, J.; Poeppel, D.; Obrig, H.; Wartenburger, I. Sensitivity of Newborn Auditory Cortex to the Temporal Structure of Sounds. J. Neurosci. 2009, 29, 14726-14733. [CrossRef] [PubMed]

94. Ouimet, T.; Foster, N.E.V.; Tryfon, A.; Hyde, K.L. Auditory-musical processing in autism spectrum disorders: A review of behavioral and brain imaging studies. Ann. N. Y. Acad. Sci. 2012, 1252, 325-331. [CrossRef] [PubMed]

95. Bouvet, L.; Simard-Meilleur, A.-A.; Paignon, A.; Mottron, L.; Donnadieu, S. Auditory local bias and reduced global interference in autism. Cognition 2014, 131, 367-372. [CrossRef] [PubMed]

96. Haigh, S.M. Variable sensory perception in autism. Eur. J. Neurosci. 2018, 47, 602-609. [CrossRef] [PubMed]

97. Di Lollo, V. Hemispheric symmetry in duration of visible persistence. Percept. Psychophys. 1981, 29, 21-25. [CrossRef] [PubMed]

98. Grabowska, A.; Nowicka, A. Visual-spatial-frequency model of cerebral asymmetry: A critical survey of behavioral and electrophysiological studies. Psychol. Bull. 1996, 120, 434-449. [CrossRef]

99. Ivry, R.B.; Robertson, L.C.; Robertson, L.C. The Two Sides of Perception; MIT Press: Cambridge, MA, USA, 1998; ISBN 978-0-262-09034-6.

100. Hochstein, S.; Ahissar, M. View from the Top: Hierarchies and Reverse Hierarchies in the Visual System. Neuron 2002, 36, 791-804. [CrossRef]

101. Ahissar, M.; Hochstein, S. The reverse hierarchy theory of visual perceptual learning. Trends Cogn. Sci. 2004, 8, 457-464. [CrossRef]

102. Ahissar, M.; Nahum, M.; Nelken, I.; Hochstein, S. Reverse hierarchies and sensory learning. Phil. Trans. R. Soc. B 2009, 364, 285-299. [CrossRef]

103. Hegde, J. Time course of visual perception: Coarse-to-fine processing and beyond. Prog. Neurobiol. 2008, 84, 405-439. [CrossRef]

104. Flevaris, A.V.; Robertson, L.C. Spatial frequency selection and integration of global and local information in visual processing: A selective review and tribute to Shlomo Bentin. Neuropsychologia 2016, 83, 192-200. [CrossRef] [PubMed] 
105. Piazza, E.A.; Silver, M.A. Relative Spatial Frequency Processing Drives Hemispheric Asymmetry in Conscious Awareness. Front. Psychol. 2017, 8. [CrossRef] [PubMed]

106. Ding, S.; Cueva, C.J.; Tsodyks, M.; Qian, N. Visual perception as retrospective Bayesian decoding from highto low-level features. Proc. Natl. Acad. Sci. USA 2017, 114, E9115-E9124. [CrossRef] [PubMed]

107. Barsalou, L.W. Grounded Cognition. Annu. Rev. Psychol. 2008, 59, 617-645. [CrossRef] [PubMed]

108. Matheson, H.E.; Barsalou, L.W. Embodiment and Grounding in Cognitive Neuroscience. In Stevens' Handbook of Experimental Psychology and Cognitive Neuroscience; Wixted, J.T., Ed.; John Wiley \& Sons, Inc.: Hoboken, NJ, USA, 2018; pp. 1-27, ISBN 978-1-119-17016-7.

109. Fischer, M.H.; Coello, Y.E. Foundations of Embodied Cognition: Conceptual and Interactive Embodiment; Routledge/Taylor \& Francis Group: New York, NY, USA, 2016; ISBN 978-1-138-80582-8.

110. Newen, A.; Bruin, L.D.; Gallagher, S. The Oxford Handbook of 4 E Cognition; Oxford University Press: Oxford, UK, 2018; ISBN 978-0-19-105435-8.

111. Felisatti, A.; Laubrock, J.; Shaki, S.; Fischer, M.H. A biological foundation for spatial-numerical associations: The brain's asymmetric frequency tuning. Ann. N. Y. Acad. Sci. 2020. [CrossRef] [PubMed]

112. Fischer, M.H. A hierarchical view of grounded, embodied, and situated numerical cognition. Cogn. Process. 2012, 13, 161-164. [CrossRef] [PubMed]

113. Pezzulo, G.; Barsalou, L.W.; Cangelosi, A.; Fischer, M.H.; McRae, K.; Spivey, M.J. Computational Grounded Cognition: A new alliance between grounded cognition and computational modeling. Front. Psychol. 2013, 3. [CrossRef]

114. Myachykov, A.; Scheepers, C.; Fischer, M.H.; Kessler, K. TEST: A Tropic, Embodied, and Situated Theory of Cognition. Top Cogn. Sci. 2014, 6, 442-460. [CrossRef]

115. Panichello, M.F.; Cheung, O.S.; Bar, M. Predictive Feedback and Conscious Visual Experience. Front. Psychol. 2013, 3. [CrossRef]

116. Park, J.; Spence, C.; Ishii, H.; Togawa, T. Turning the other cheek: Facial orientation influences both model attractiveness and product evaluation. Psychol. Mark. 2020. [CrossRef]

117. Larsson, M.L. Binocular vision, the optic chiasm, and their associations with vertebrate motor behavior. Front. Ecol. Evol. 2015, 3. [CrossRef]

118. Shaki, S.; Fischer, M.H. Systematic spatial distortion of quantitative estimates. Psychol. Res. 2020. [CrossRef] [PubMed]

119. Fischer, M.H.; Shaki, S. Spatial Associations in Numerical Cognition-From Single Digits to Arithmetic. Q. J. Exp. Psychol. 2014, 67, 1461-1483. [CrossRef] [PubMed]

120. Göbel, S.M.; Shaki, S.; Fischer, M.H. The Cultural Number Line: A Review of Cultural and Linguistic Influences on the Development of Number Processing. J. Cross-Cult. Psychol. 2011, 42, 543-565. [CrossRef]

121. Rugani, R.; de Hevia, M.-D. Number-space associations without language: Evidence from preverbal human infants and non-human animal species. Psychon. Bull. Rev. 2017, 24, 352-369. [CrossRef]

122. Cipora, K.; Schroeder, P.A.; Soltanlou, M.; Nuerk, H.-C. More Space, Better Mathematics: Is Space a Powerful Tool or a Cornerstone for Understanding Arithmetic? In Visualizing Mathematics; Mix, K.S., Battista, M.T., Eds.; Research in Mathematics Education; Springer International Publishing: Cham, Switzerland, 2018; pp. 77-116, ISBN 978-3-319-98766-8.

123. Di Giorgio, E.; Lunghi, M.; Rugani, R.; Regolin, L.; Dalla Barba, B.; Vallortigara, G.; Simion, F. A mental number line in human newborns. Dev. Sci. 2019, 22. [CrossRef]

124. Rugani, R.; Vallortigara, G.; Priftis, K.; Regolin, L. Number-space mapping in the newborn chick resembles humans' mental number line. Science 2015, 347, 534-536. [CrossRef]

125. Nemeh, F.; Humberstone, J.; Yates, M.J.; Reeve, R.A. Non-symbolic magnitudes are represented spatially: Evidence from a non-symbolic SNARC task. PLoS ONE 2018, 13, e0203019. [CrossRef]

126. Zhou, X.; Shen, C.; Li, L.; Li, D.; Cui, J. Mental Numerosity Line in the Human's Approximate Number System. Exp. Psychol. 2016, 63, 169-179. [CrossRef]

127. Mitchell, T.; Bull, R.; Cleland, A.A. Implicit response-irrelevant number information triggers the SNARC effect: Evidence using a neural overlap paradigm. Q. J. Exp. Psychol. 2012, 65, 1945-1961. [CrossRef]

128. Dehaene, S.; Bossini, S.; Giraux, P. The mental representation of parity and number magnitude. J. Exp. Psychol. Gen. 1993, 122, 371-396. [CrossRef]

129. Rugani, R.; Vallortigara, G.; Priftis, K.; Regolin, L. Numerical magnitude, rather than individual bias, explains spatial numerical association in newborn chicks. eLife 2020, 9, e54662. [CrossRef] [PubMed] 
130. Bulf, H.; de Hevia, M.D.; Cassia, V.M. Small on the left, large on the right: Numbers orient visual attention onto space in preverbal infants. Dev. Sci. 2016, 19, 394-401. [CrossRef] [PubMed]

131. Bulf, H.; Cassia, V.M.; de Hevia, M.D. Are Numbers, Size and Brightness Equally Efficient in Orienting Visual Attention? Evidence from an Eye-Tracking Study. PLoS ONE 2014, 9, e99499. [CrossRef] [PubMed]

132. Perry, C.; Zorzi, M.; Ziegler, J.C. Understanding Dyslexia Through Personalized Large-Scale Computational Models. Psychol. Sci. 2019, 30, 386-395. [CrossRef] [PubMed]

133. Arnett, A.B.; Pennington, B.F.; Peterson, R.L.; Willcutt, E.G.; DeFries, J.C.; Olson, R.K. Explaining the sex difference in dyslexia. J. Child Psychol. Psychiatr. 2017, 58, 719-727. [CrossRef]

134. Badian, N.A. Persistent arithmetic, reading, or arithmetic and reading disability. Ann. Dyslexia 1999, 49, 43-70. [CrossRef]

135. Barbaresi, W.J.; Katusic, S.K.; Colligan, R.C.; Weaver, A.L.; Jacobsen, S.J. Math Learning Disorder: Incidence in a Population-Based Birth Cohort, 1976-82, Rochester, Minn. Ambul. Pediatrics 2005, 5, 281-289. [CrossRef]

136. Dirks, E.; Spyer, G.; van Lieshout, E.C.D.M.; de Sonneville, L. Prevalence of Combined Reading and Arithmetic Disabilities. J. Learn. Disabil. 2008, 41, 460-473. [CrossRef]

137. Lewis, C.; Hitch, G.J.; Walker, P. The Prevalence of Specific Arithmetic Difficulties and Specific Reading Difficulties in 9- to 10-year-old Boys and Girls. J. Child Psychol. Psychiat. 1994, 35, 283-292. [CrossRef]

138. Landerl, K.; Fussenegger, B.; Moll, K.; Willburger, E. Dyslexia and dyscalculia: Two learning disorders with different cognitive profiles. J. Exp. Child Psychol. 2009, 103, 309-324. [CrossRef] [PubMed]

139. Bradley, L.; Bryant, P.E. Categorizing sounds and learning to read-A causal connection. Nature 1983, 301, 419-421. [CrossRef]

140. Boets, B.; de Beeck, H.P.O.; Vandermosten, M.; Scott, S.K.; Gillebert, C.R.; Mantini, D.; Bulthe, J.; Sunaert, S.; Wouters, J.; Ghesquiere, P. Intact But Less Accessible Phonetic Representations in Adults with Dyslexia. Science 2013, 342, 1251-1254. [CrossRef] [PubMed]

141. Stein, J. What is Developmental Dyslexia? Brain Sci. 2018, 8, 26. [CrossRef] [PubMed]

142. Franceschini, S.; Bertoni, S.; Gianesini, T.; Gori, S.; Facoetti, A. A different vision of dyslexia: Local precedence on global perception. Sci. Rep. 2017, 7, 17462. [CrossRef]

143. Franceschini, S.; Bertoni, S.; Puccio, G.; Mancarella, M.; Gori, S.; Facoetti, A. Local perception impairs the lexical reading route. Psychol. Res. 2020. [CrossRef]

144. Hickok, G.; Poeppel, D. The cortical organization of speech processing. Nat. Rev. Neurosci. 2007, 8, $393-402$. [CrossRef]

145. Sammler, D.; Grosbras, M.-H.; Anwander, A.; Bestelmeyer, P.E.G.; Belin, P. Dorsal and Ventral Pathways for Prosody. Curr. Biol. 2015, 25, 3079-3085. [CrossRef]

146. Skottun, B.C. On the use of spatial frequency to isolate contributions from the magnocellular and parvocellular systems and the dorsal and ventral cortical streams. Neurosci. Biobehav. Rev. 2015, 56, 266-275. [CrossRef]

147. Grinter, E.J.; Maybery, M.T.; Badcock, D.R. Vision in developmental disorders: Is there a dorsal stream deficit? Brain Res. Bull. 2010, 82, 147-160. [CrossRef]

148. Van der Hallen, R.; Evers, K.; Brewaeys, K.; Van den Noortgate, W.; Wagemans, J. Global processing takes time: A meta-analysis on local-global visual processing in ASD. Psychol. Bull. 2015, 141, 549-573. [CrossRef] [PubMed]

149. Geschwind, N. Disconnexion Syndromes in Animals and Man. Brain 1965, 88, 585. [CrossRef] [PubMed]

150. Gazzaniga, M.S. Right hemisphere language following brain bisection: A 20-year perspective. Am. Psychol. 1983, 38, 525-537. [CrossRef] [PubMed]

151. Hofstadter, D.R. Gödel, Escher, Bach: An Eternal Golden Braid; Penguin Books Ltd.: Middlesex, UK, 1979.

152. Peretz, I. Neurobiology of Congenital Amusia. Trends Cogn. Sci. 2016, 20, 857-867. [CrossRef] [PubMed]

153. Peretz, I.; Hyde, K.L. What is specific to music processing? Insights from congenital amusia. Trends Cogn. Sci. 2003, 7, 362-367. [CrossRef]

154. Friederici, A.D.; Alter, K. Lateralization of auditory language functions: A dynamic dual pathway model. Brain Lang. 2004, 89, 267-276. [CrossRef]

155. Norton, A.; Zipse, L.; Marchina, S.; Schlaug, G. Melodic Intonation Therapy: Shared Insights on How It Is Done and Why It Might Help. Ann. N. Y. Acad. Sci. 2009, 1169, 431-436. [CrossRef]

156. Albouy, P.; Benjamin, L.; Morillon, B.; Zatorre, R.J. Distinct sensitivity to spectrotemporal modulation supports brain asymmetry for speech and melody. Science 2020, 367, 1043-1047. [CrossRef] 
157. Happé, F.; Cook, J.L.; Bird, G. The Structure of Social Cognition: In(ter)dependence of Sociocognitive Processes. Annu. Rev. Psychol. 2017, 68, 243-267. [CrossRef]

158. Kennedy, D.P.; Adolphs, R. The social brain in psychiatric and neurological disorders. Trends Cogn. Sci. 2012, 16, 559-572. [CrossRef]

159. McCarthy, G.; Puce, A.; Gore, J.C.; Allison, T. Face-Specific Processing in the Human Fusiform Gyrus. J. Cogn. Neurosci. 1997, 9, 605-610. [CrossRef] [PubMed]

160. Gazzaniga, M.S.; Smylie, C.S. Facial recognition and brain asymmetries: Clues to underlying mechanisms. Ann. Neurol. 1983, 13, 536-540. [CrossRef] [PubMed]

161. Meng, M.; Cherian, T.; Singal, G.; Sinha, P. Lateralization of face processing in the human brain. Proc. R. Soc. B 2012, 279, 2052-2061. [CrossRef] [PubMed]

162. Caharel, S.; Leleu, A.; Bernard, C.; Viggiano, M.-P.; Lalonde, R.; Rebaï, M. Early holistic face-like processing of Arcimboldo paintings in the right occipito-temporal cortex: Evidence from the N170 ERP component. Int. J. Psychophysiol. 2013, 90, 157-164. [CrossRef] [PubMed]

163. Kobayashi, M.; Otsuka, Y.; Nakato, E.; Kanazawa, S.; Yamaguchi, M.K.; Kakigi, R. Do infants recognize the Arcimboldo images as faces? Behavioral and near-infrared spectroscopic study. J. Exp. Child Psychol. 2012, 111, 22-36. [CrossRef] [PubMed]

164. Goffaux, V.; Rossion, B. Faces are "spatial"-Holistic face perception is supported by low spatial frequencies. J. Exp. Psychol. Human Percept. Perform. 2006, 32, 1023-1039. [CrossRef]

165. Stein, T.; Seymour, K.; Hebart, M.N.; Sterzer, P. Rapid Fear Detection Relies on High Spatial Frequencies. Psychol. Sci. 2014, 25, 566-574. [CrossRef]

166. Johnson, M.H. Subcortical face processing. Nat. Rev. Neurosci. 2005, 6, 766-774. [CrossRef]

167. Öhman, A. The role of the amygdala in human fear: Automatic detection of threat. Psychoneuroendocrinology 2005, 30, 953-958. [CrossRef]

168. Tamietto, M.; de Gelder, B. Neural bases of the non-conscious perception of emotional signals. Nat. Rev. Neurosci. 2010, 11, 697-709. [CrossRef]

169. Blom, S.S.A.H.; Aarts, H.; Semin, G.R. Lateralization of facial emotion processing and facial mimicry. Laterality 2020, 25, 259-274. [CrossRef] [PubMed]

170. Bourne, V.J. How are emotions lateralised in the brain? Contrasting existing hypotheses using the Chimeric Faces Test. Cogn. Emot. 2010, 24, 903-911. [CrossRef]

171. Demaree,H.A.; Everhart, D.E.; Youngstrom, E.A.; Harrison, D.W. Brain Lateralization of Emotional Processing: Historical Roots and a Future Incorporating “Dominance". Behav. Cogn. Neurosci. Rev. 2005, 4, 3-20. [CrossRef] [PubMed]

172. Ahern, G.L.; Schwartz, G.E. Differential lateralization for positive and negative emotion in the human brain: EEG spectral analysis. Neuropsychologia 1985, 23, 745-755. [CrossRef]

173. Davidson, R.J. Well-being and affective style: Neural substrates and biobehavioural correlates. Phil. Trans. R. Soc. Lond. B 2004, 359, 1395-1411. [CrossRef]

174. Packheiser, J.; Rook, N.; Dursun, Z.; Mesenhöller, J.; Wenglorz, A.; Güntürkün, O.; Ocklenburg, S. Embracing your emotions: Affective state impacts lateralisation of human embraces. Psychol. Res. 2019, 83, 26-36. [CrossRef]

175. Gordon, I.E. Left and right in Goya's portraits. Nature 1974, 249, 197-198. [CrossRef]

176. Mcmanus, I.C.; Humphrey, N.K. Turning the Left Cheek. Nature 1973, 243, 271-272. [CrossRef]

177. Pérez González, C. Lateral organisation in nineteenth-century studio photographs is influenced by the direction of writing: A comparison of Iranian and Spanish photographs. Laterality Asymmetries Body Brain Cogn. 2012, 17, 515-532. [CrossRef]

178. Chahboun, S.; Flumini, A.; González, C.P.; McManus, I.C.; Santiago, J. Reading and writing direction effects on the aesthetic appreciation of photographs. Laterality Asymmetries Body Brain Cogn. 2017, 22, 313-339. [CrossRef] [PubMed]

179. Powell, W.R.; Schirillo, J.A. Asymmetrical facial expressions in portraits and hemispheric laterality: A literature review. Laterality Asymmetries Body Brain Cogn. 2009, 14, 545-572. [CrossRef] [PubMed]

180. Lindell, A.K. The silent social/emotional signals in left and right cheek poses: A literature review. Laterality Asymmetries Body Brain Cogn. 2013, 18, 612-624. [CrossRef] [PubMed]

181. Lindell, A.K. Consistently Showing Your Best Side? Intra-individual Consistency in\# Selfie Pose Orientation. Front. Psychol. 2017, 8, 26. [CrossRef] 
182. Manovich, L.; Ferrari, V.; Bruno, N. Selfie-Takers Prefer Left Cheeks: Converging Evidence from the (Extended) selfiecity Database. Front. Psychol. 2017, 8, 1460. [CrossRef]

183. Wickens, T.; Palmer, S.; Gardner, J. Aesthetic issues in spatial composition: Effects of position and direction on framing single objects. Spat. Vis. 2008, 21, 421-449. [CrossRef]

184. Benjafield, J.; Segalowitz, S.J. Left and Right in Leonardo's Drawings of Faces. Empir. Stud. Arts 1993, 11, 25-32. [CrossRef]

185. Christman, S.; Pinger, K. Lateral Biases in Aesthetic Preferences: Pictorial Dimensions and Neural Mechanisms. Laterality Asymmetries Body Brain Cogn. 1997, 2, 155-175. [CrossRef]

186. Busin, Y.; Lukasova, K.; Asthana, M.K.; Macedo, E.C. Hemiface Differences in Visual Exploration Patterns When Judging the Authenticity of Facial Expressions. Front. Psychol. 2018, 8, 2332. [CrossRef]

187. Yamamoto, M.; Kowatari, Y.; Ueno, S.; Yamane, S.; Kitazawa, S. Accelerated recognition of left oblique views of faces. Exp. Brain Res. 2005, 161, 27-33. [CrossRef]

188. Hayes, T.; Muday, J.A.; Schirillo, J.A. Portrait hemispheric laterality measured using pupil diameter and aesthetic judgments. Psychol. Aesthet. Creat. Arts 2013, 7, 276-284. [CrossRef]

189. Grüsser, O.-J.; Selke, T.; Zynda, B. Cerebral Lateralization and Some Implications for Art, Aesthetic Perception, and Artistic Creativity. In Beauty and the Brain: Biological Aspects of Aesthetics; Rentschler, I., Herzberger, B., Epstein, D., Eds.; Birkhäuser: Basel, Switzerland, 1988; pp. 257-293, ISBN 978-3-0348-6350-6.

190. Lindell, A.K.; Savill, N.J. Time to turn the other cheek? The influence of left and right poses on perceptions of academic specialisation. Laterality Asymmetries Body Brain Cogn. 2010, 15, 639-650. [CrossRef] [PubMed]

191. Nicholls, M.E.R.; Clode, D.; Wood, S.J.; Wood, A.G. Laterality of expression in portraiture: Putting your best cheek forward. Proc. R. Soc. Lond. B 1999, 266, 1517-1522. [CrossRef] [PubMed]

192. Nicholls, M.E.; Roberts, G.R. Can Free-Viewing Perceptual Asymmetries be Explained by Scanning, Pre-Motor or Attentional Biases? Cortex 2002, 38, 113-136. [CrossRef]

193. Roether, C.L.; Omlor, L.; Giese, M.A. Lateral asymmetry of bodily emotion expression. Curr. Biol. 2008, 18, R329-R330. [CrossRef] [PubMed]

194. Chokron, S.; De Agostini, M. Reading habits influence aesthetic preference. Cogn. Brain Res. 2000, 10, 45-49. [CrossRef]

195. Friedrich, T.E.; Elias, L.J. The write bias: The influence of native writing direction on aesthetic preference biases. Psychol. Aesthet. Creat. Arts 2016, 10, 128-133. [CrossRef]

196. Nachson, I.; Argaman, E.; Luria, A. Effects of Directional Habits and Handedness on Aesthetic Preference for Left and Right Profiles. J. Cross-Cult. Psychol. 1999, 30, 106-114. [CrossRef]

197. Smith, A.K.; Duerksen, K.N.; Gutwin, C.; Elias, L.J. Lateral biases in aesthetic and spatial location judgments: Differences between tasks and native reading directions. Laterality 2020, 25, 5-21. [CrossRef]

198. Page, A.G.; McManus, C.; González, C.P.; Chahboun, S. Is Beauty in the Hand of the Writer? Influences of Aesthetic Preferences through Script Directions, Cultural, and Neurological Factors: A Literature Review. Front. Psychol. 2017, 8, 1325. [CrossRef]

199. Beaumont, J.G. Lateral organization and aesthetic preference: The importance of peripheral visual asymmetries. Neuropsychologia 1985, 23, 103-113. [CrossRef]

200. Levy, J. Lateral dominance and aesthetic preference. Neuropsychologia 1976, 14, 431-445. [CrossRef]

201. Gaffron, M. Left and right in pictures. Art Q. 1950, 13, 312-321.

202. Kliegl, R.; Laubrock, J.; Köstler, A. Augenblicke bei der Bildbetrachtung. Eine kognitionswissenschaftliche Spekulation zum Links und Rechts im Bild. In Räume-Bilder-Kulturen; Lepper, V.M., Deuflhard, P., Markschies, C., Eds.; de Gruyter: Berlin, Germany, 2015; pp. 77-90.

203. Mead, A.M.; McLaughlin, J.P. The roles of handedness and stimulus asymmetry in aesthetic preference. Brain Cogn. 1992, 20, 300-307. [CrossRef]

204. Maass, A.; Pagani, D.; Berta, E. How Beautiful is the Goal and How Violent is the Fistfight? Spatial Bias in the Interpretation of Human Behavior. Soc. Cogn. 2007, 25, 833-852. [CrossRef]

205. Flath, M.E.; Smith, A.K.; Elias, L.J. Cultural differences in lateral biases on aesthetic judgments: The effect of native reading direction. Cult. Brain 2019, 7, 57-66. [CrossRef]

206. Rodway, P.; Schepman, A.; Crossley, B.; Lee, J. A leftward perceptual asymmetry when judging the attractiveness of visual patterns. Laterality Asymmetries Body Brain Cogn. 2019, 24, 1-25. [CrossRef]

207. Cajar, A.; Engbert, R.; Laubrock, J. How spatial frequencies and color drive object search in real-world scenes: A new eye-movement corpus. J. Vis. 2020, 20, 8. [CrossRef] 
208. Cajar, A.; Engbert, R.; Laubrock, J. Spatial frequency processing in the central and peripheral visual field during scene viewing. Vis. Res. 2016, 127, 186-197. [CrossRef]

209. Cajar, A.; Schneeweiß, P.; Engbert, R.; Laubrock, J. Coupling of attention and saccades when viewing scenes with central and peripheral degradation. J. Vis. 2016, 16, 8. [CrossRef]

210. Engbert, R.; Nuthmann, A.; Richter, E.M.; Kliegl, R. SWIFT: A Dynamical Model of Saccade Generation during Reading. Psychol. Rev. 2005, 112, 777-813. [CrossRef]

211. Kliegl, R.; Risse, S.; Laubrock, J. Preview benefit and parafoveal-on-foveal effects from word $\mathrm{n}+2$. J. Exp . Psychol. Human Percept. Perform. 2007, 33, 1250-1255. [CrossRef] [PubMed]

212. Pan, J.; Yan, M.; Laubrock, J. Semantic preview benefit and cost: Evidence from parafoveal fast-priming paradigm. Cognition 2020, 205, 104452. [CrossRef] [PubMed]

213. Reichle, E.D.; Pollatsek, A.; Fisher, D.L.; Rayner, K. Toward a Model of Eye Movement Control in Reading. Psychol. Rev. 1998, 105, 125. [CrossRef] [PubMed]

214. Piazza, M.; Facoetti, A.; Trussardi, A.N.; Berteletti, I.; Conte, S.; Lucangeli, D.; Dehaene, S.; Zorzi, M. Developmental trajectory of number acuity reveals a severe impairment in developmental dyscalculia. Cognition 2010, 116, 33-41. [CrossRef]

215. Zorzi, M.; Testolin, A. An emergentist perspective on the origin of number sense. Phil. Trans. R. Soc. B 2018, 373. [CrossRef]

216. De Hevia, M.D.; Veggiotti, L.; Streri, A.; Bonn, C.D. At Birth, Humans Associate "Few" with Left and "Many" with Right. Curr. Biol. 2017, 27, 3879-3884. [CrossRef]

217. Märker, G.; Learmonth, G.; Thut, G.; Harvey, M. Intra- and inter-task reliability of spatial attention measures in healthy older adults. PLoS ONE 2019, 14, e0226424. [CrossRef]

Publisher's Note: MDPI stays neutral with regard to jurisdictional claims in published maps and institutional affiliations. 